\title{
Electrochemical Sensors for Pharmaceutical and Environmental Analysis
}

\author{
Robert Săndulescu, Cecilia Cristea, Veronica Hârceagă and Ede Bodoki \\ "Iuliu Hațieganu" University of Medicine and Pharmacy Cluj-Napoca, \\ Romania
}

\section{Introduction}

Improvement of life quality is one of the most important objectives of the global research efforts. Naturally, the quality of life is closely related to a better control of diseases, drug and food quality and safety, and last but not least, of the quality of our environment. In all these fields, a continuous, sensitive, fast and reliable monitoring is required to control key parameters (Castillo et al., 2004). In this context, the use of sensors and biosensors represent very promising tools. The interest in their application in the biomedical, pharmaceutical and environmental field increased lately as a result of their sensitivity, specificity and simple use, providing fast, cost-effective and repetitive measurements with miniaturized and portable devices.

\section{How to construct and optimize an enzyme electrochemical biosensor?}

A biosensor, according to the IUPAC definition, is a self-contained integrated device, which is capable of providing specific quantitative or semi-quantitative analytical information using a biological recognition element (biochemical receptor) which is retained in spatial contact with a physical transduction element (Thevenot et al., 2001). Actually they transform the reaction between the analyte and the biological component into a signal detected and monitored by the transducer that reflects the concentration of the analyte. Biosensors may be classified according to the bioactive component or the recognition event, the mode of signal transduction or according to the immobilization technique.

In the construction of the biosensors the biocomponent is selected depending on the application and the performance criteria requested. The most commonly applied bioactive components are the enzymes. They rapidly and cleanly form selective bonds with the substrates and convert them into products. One of the major issues when working with enzymes is their stability. Enzymes are very sensitive to their environment. Deactivation, inhibition or unfolding upon adsorption and chemical or thermal inactivation are common (Grieshaber et al. 2008). There are several advantages of the enzyme biosensors. These include their availability and the ability to modify the catalytic properties or substrate specificity by means of genetic engineering and catalytic amplification of the biosensor response by modulation of the enzyme activity with respect to the target analyte (Rogers, 2006). Among the enzymes commercially available, the oxidases: the glucose oxidase (GOD) and horseradish peroxidase (HRP) are the most often used. This type of enzyme offers the 
advantages of being stable and in some situations does not require coenzymes or cofactors. Other, less commonly used enzymes comprise beta-lactamase, urease, tyrosinase and acetylcholinesterase or choline oxidase.

Among different transducers employed in biosensors construction, the electrochemical transducers are the most frequently used. They occupy the first position as far as the disponibility on the market and they have already demonstrated their practical utility.

The most well known enzyme electrochemical biosensors reported in the literature are the biosensors with glucose oxidase for the detection of glucose (Ammam et al., 2010), the biosensors with HRP for the detection of compounds which can be peroxidate like clozapine, (Yu et al., 2006a), acetaminophen, (Sima et al., 2008) and of the thiolic products (gluthation, N-acetilcysteine) (Yu et al., 2006b) and the biosensors with acetylcholine and choline oxidase for detection of drugs used in Alzheimer treatment (Lenigk et al., 2000) and the organophosphorus pesticides (Andreescu \& Marty, 2006).

The most important step in building a biosensor is the immobilization of the biomolecules. As a matter of fact the immobilization technique determines the biosensor performances. The selection of an appropriate immobilization method depends on the nature of the biological element, type of the transducer used, physicochemical properties of the analyte and operating conditions for the biosensor.

The purpose of any immobilization method is to get high stability and efficiency from the biosensor. The biocomponent should be stably immobilized in a physical environment close to the natural enzyme's environment in order to retain maximum functionality of its biological activity on the surface of the transducer. The immobilization might involve a number of disadvantages such as: worsening the performance of enzymatic system, lowering and even lost of activity, increase of Michaelis constant, modification of the optimal working temperature and $\mathrm{pH}$ of the enzyme in comparison with the free form. All these, however, may be reduced by applying an appropriate design.

The system should assure also good diffusion properties for substrates and should establish satisfactory electrical communication between the active component and the electrode surface (Xu et al., 2006) in order to give the electrochemical output signal required.

When the design of a biosensor is built, all the characteristics of an ideal analytical system: selectivity, limit of detection and limit of quantification, sensitivity, reliability, repetitively, robustness, throughput, reagentless, simplicity, costs, miniaturization and portability have to be taken into account and also the performances and the drawbacks of the systems already reported in the literature for the analyte of interest have to be deeply studied.

Enzyme biosensors can be categorized into those that monitor the catalytic transformation of a target analyte by a specific enzyme or the enzyme biological activity by measuring the producing or consumption of a given analyte and those that monitor the inhibition of a biochemical reaction due to the presence of target analyte. The inhibition-based biosensors can be designed in two different ways: the inhibitor interacts directly with the enzyme, blocking its activity, or the inhibitor interacts with a product of the enzymatic reaction. Only specific enzyme inhibitors should be regarded as "true inhibitors", which bind to the enzyme and inhibit its activity. However, the definition of "enzyme inhibitors" is sometimes misleading, for example in the case of tyrosinase based biosensors, the terminology being also used to refer to melanogenesis process inhibitors, whose action mainly reside in some interference in melanin formation, regardless of any direct inhibitor-enzyme interaction (Chang et al., 2009). "True tyrosinase inhibitors" can be considered kojic acid that links to the active site of tyrosinase like a copper chelator (Briganti et al., 1990), benzoic acid that 
functions as a monophenol analog, binding to one copper ion of the binuclear site via its carboxylate group (Menon et al., 1990) and azelaic acid that blocks the access of the substrate to the enzyme active center (Briganti et al.,1990) but not ascorbic acid that interrupts melanin synthesis process by reducing the enzymatically generated dopaquinone intermediate back to L-dopa.

When a biosensor applied to pharmaceutical or biomedical analysis is described the biological processes have to be studied in detail, taking in consideration their complexity, in order to clearly outline the field of application and the limitations of the device. For example the biosensor described by Sima et al. (2011) allowed the quantification and the characterization of inhibitors from the point of view of their interaction with tyrosinase and the enzymatic reaction in the presence of the natural substrate L-tyrosine. In the skin pigmentation process these compounds may interfere also in other biochemical steps having as final result a decrease in melanin formation. For example, azelaic acid inhibits melanin formation through other mechanism besides its interaction with the tyrosinase active site. It may also interfere with DNA synthesis and mitochondria activity in hyperactive and abnormal melanocytes (Briganti et al., 1990).

Once the biocomponent, the transducer and the immobilization technique are chosen the operation mode of the device should be established. For example in the article published by Sima et al., (2011), the obtained configuration was used to monitor the reduction current of the enzymatically generated oxidized species of L-tyrosine, i.e. the dopaquinone, in the presence of molecular oxygen (Fig. 1).

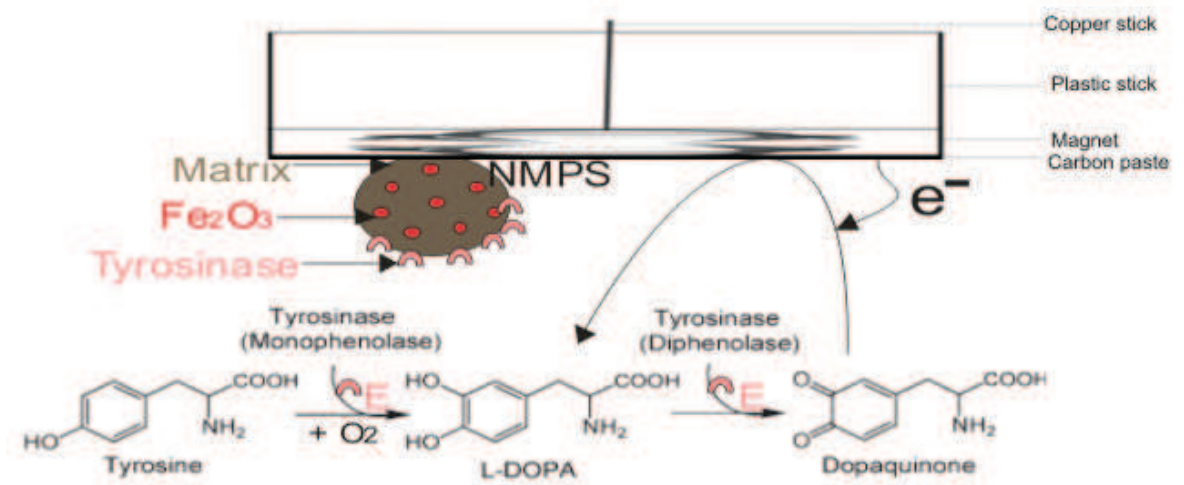

Fig. 1. Biosensor's mechanism of action (Sima et al., 2011)

The inhibition-based biosensors are preferred, if possible, in order to assure a good reproducibility of the results because in this case, when the analytes are evaluated, the biosensor inhibition signal is normalized to the initial signal of the substrate for each curve. Thus, the final results are not influenced by the variations of substrate's signal which can occur due to the loss of the enzyme activity or due to random errors that can appear during biosensor's preparation.

Also blank experiments have to be performed in order to check if "the biosensor" without enzyme or the inhibition based biosensor operating without addition of the enzymatic substrate does not give any response under the selected experimental conditions and in the presence of the studied compounds. 
If the developed device is a novel analytical tool, in order to test its efficiency, it should be applied to the study of compounds that have already demonstrated their activity in clinical practice or by using other analytical methods, as it was the case in the article published by Sima et al. (2011).

When testing different compounds, because there are many factors which contribute to the final results (type of enzyme, quantity of immobilized enzyme, immobilization method, type of substrate, substrate concentration, time of contact between the enzyme, substrate and inhibitor, $\mathrm{pH}$, temperature, applied potential, rate of solution stirring), in order to obtain a correct comparison of the studied compounds, the experiments have to be performed under the same experimental conditions (Sima et al., 2011).

First the working conditions for an optimal response to substrate of the enzyme based biosensor have to be tested. If the biosensor is designed for testing biologically active compounds it has to be taken into account that the device should operate as close as possible to the natural enzyme's environment.

The working applied potential, the type of enzyme substrate, the buffer $\mathrm{pH}$, the quantity of immobilized enzyme, the substrate concentration in case of the inhibition studies, the presence of cofactors if necessary; all these have to be considered.

In order to select the applied potential for the amperometric testing, first of all, the biological process that produces electroactive compounds has to be demonstrated under the experimental conditions, even though it is well know in its natural environment. Normally cyclic voltammetric experiments are performed for detecting the electrochemical reduction or oxidation potential of the enzymatically generated electroactive species (Yu et al., 2006). It may be sometimes the case that if low reduction or oxidation currents are generated they might not be detected in cyclic voltammetric experiments, so amperometry is recommended, thanks to its low background currents (Shan et al., 2008). The applied potential has to be considered taking into account the magnitude of the electrochemical signals, the ratio between signal and background current, the steady-state of the response plateau, the possible interfering species at that applied potential and also, the working potential of other similar biosensors described in the literature.

When selecting the enzymatic substrate in case of inhibition based biosensors, this has to be the same as in the biological process, if possible, because it has been demonstrated that the potency of inhibitors varies considerably depending on the characteristics of the substrate (Shan et al., 2008). The sensitivity of the response has to be high enough and the steady-state of the response plateau has to be stable for assuring reliable results and the lag period of the enzymatic step sufficiently short for further readily implementation of the testing conditions.

It is well known that enzyme activity is highly $\mathrm{pH}$ dependent and that the optimum $\mathrm{pH}$ for an enzymatic assay must be determined empirically (Amine et al., 2006). The buffer $\mathrm{pH}$ considered optimal has to be chosen taking in consideration the magnitude of the amperometric signal, the steady-state of the response, the enzyme stability $\mathrm{pH}$, the normal biological $\mathrm{pH}$ of the process and other similar biosensors reported in the literature.

The amount of enzyme immobilized at the electrode surface has to offer a good sensitivity and repeatability of the biosensor response taking in consideration also the costs of the assay, since some enzymes can be quite expensive.

The opinions about the substrate concentration to be considered in inhibition assays are quite contradictory. Kok et al. (2002), concluded, when measuring the inhibition potency of a competitive inhibitor with an acetylcholinesterase and a choline oxidase biosensor, that the 
inhibition percentage increased by raising the substrate concentration. Therefore they worked in enzyme saturated substrate conditions. Shan et al. (2008) demonstrated that for a tyrosinase biosensor for the determination of benzoic acid, the concentration of the catechol substrate did not affect the maximum inhibition percentage but it affected the sensitivity of the method. It must be noted, however, that the use of a high substrate concentration would not yield sensitive inhibition responses when the quantification of a competitive inhibitor is performed by simultaneous addition of the inhibitor and the substrate. Because in competitive inhibition the substrate competes with the inhibitor for the enzyme active site, and the inhibition, especially at low inhibitor concentrations, would likely not be detected (Kok et al., 2002). In the case of the biosensor made by Sima et al. (2011) as it was not designed for the quantification of inhibitors but for the screening and quantification of their inhibitory potency, it was considered that all the immobilized enzyme molecules must take part in the reaction and this could only be possible in substrate concentration corresponding to the saturation portion of the activity versus substrate curve. When the concentration of substrate is quite high, it has to be established if the concentration of other cofactors participating in the reaction is not a limiting factor and that the enzymatic process is saturated by the substrate.
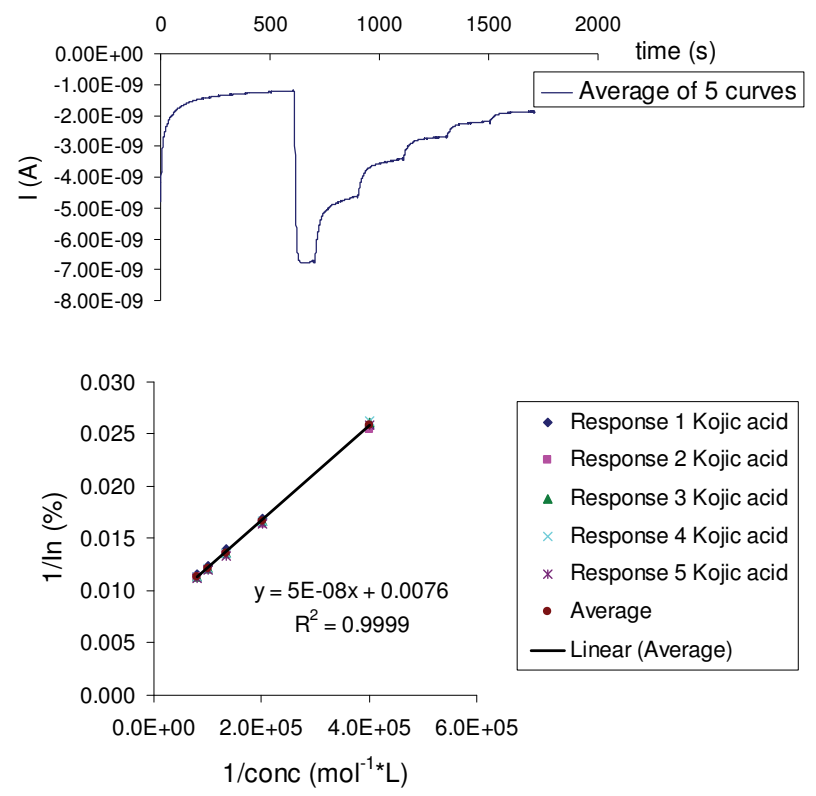

Fig. 2. Tyrosinase based biosensor amperometric response. L-tyrosine $3.33 \cdot 10^{-4} \mathrm{M}$, Kojic acid inhibitor between $2.50 \cdot 10^{-6}$ and $1.24 \cdot 10^{-5} \mathrm{M}, 0.1 \mathrm{M}$ phosphate buffer $\mathrm{pH} 6.5$, Eapp $-100 \mathrm{mV}$, $10 \mu \mathrm{L}$ of a $1.25 \mathrm{mg} / \mathrm{mL}$ tyrosinase-NMPS suspension spiked onto the mCPE. Insert: inhibition calibration curve (Sima et al., 2011)

In case of electrochemical biosensors parameters like apparent Michaelis-Menten constant $\left(\mathrm{K}_{\mathrm{m}} \mathrm{app}\right)$, maximum current intensity, limit of detection and linear range for the analyte of interest have to be determined. 
In case of electrochemical inhibition based biosensors parameters like $\mathrm{IC}_{50}, \mathrm{~K}_{\mathrm{i}}$ app (inhibition constant) and mechanism of inhibition of the studied compounds have to be determined.

In order to determine $\mathrm{IC}_{50}$, the concentration of inhibitor which inhibits $50 \%$ of the substrate signal, the concentration of inhibitors can be correlated with the percentage of inhibition (In $\%)$ which can be calculated using the relationship: $\operatorname{In}(\%)=\left[\left(I_{0}-I_{1}\right) / I_{0}\right] \times 100$; with $I_{0}$ and $I_{1}$ being the biosensor current signals before and after the addition of the inhibitor, respectively (Fig. 2).

The mechanism of inhibition can be established from the relationship between the biosensor response to substrate, $\mathrm{K}_{\mathrm{m}}$ app and $\mathrm{I}_{\max }$ in the absence and in the presence of different concentrations of inhibitor added in the initial testing solution (Fig. 3).

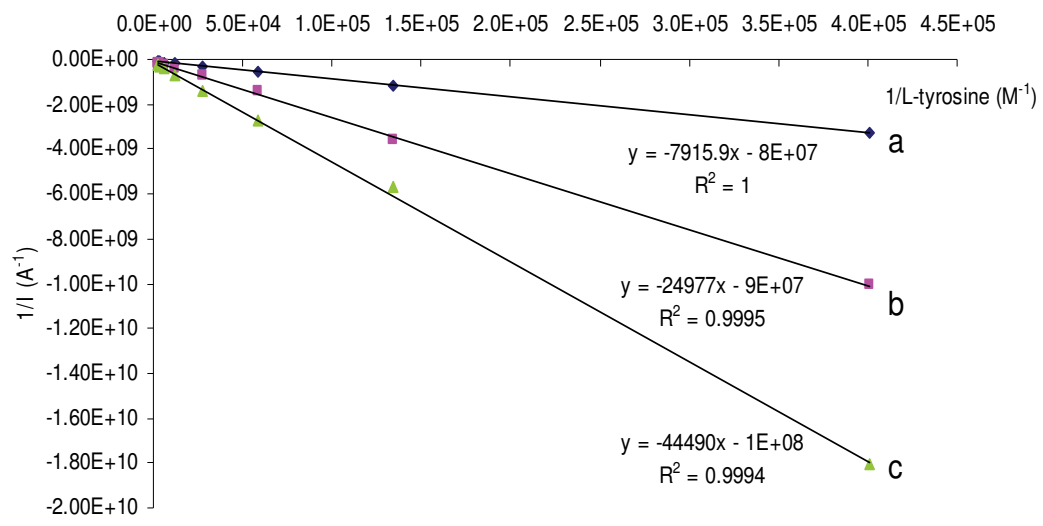

Fig. 3. Tyrosinase based biosensor amperometric data: 1/Signal vs 1/[L-tyrosine]. L-tyrosine between $2.48 \cdot 10^{-6}-4.39 \cdot 10^{-4} \mathrm{M}$ a. without Kojic acid, b. in the presence of $2.09 \cdot 10^{-6} \mathrm{M}$ Kojic acid, c. in the presence of $4.18 \cdot 10^{-6} \mathrm{M}$ Kojic acid, $0.1 \mathrm{M}$ phosphate buffer $\mathrm{pH} 6.5$, Eapp - $100 \mathrm{mV}, 10 \mu \mathrm{L}$ of a $1.25 \mathrm{mg} / \mathrm{mL}$ tyrosinase-NMPS suspension deposited onto the mCPE (Sima et al., 2011)

From the primary plot of $1 / \mathrm{I}\left(\mathrm{A}^{-1}\right)$ versus 1 / substrate concentration ( $\left.\mathrm{M}^{-1}\right)$ (Lineweaver-Burk), secondary plots can be generated, by plotting the slopes from the primary plots versus inhibitor concentration in order to determine the apparent inhibition constant, $\mathrm{K}_{\mathrm{i}}^{\mathrm{app}}$ (Fig. 4). Finally the long-term stability of the immobilized enzyme has to be evaluated by measuring the biosensor response to substrate. Normally when not in use, the enzyme has to be maintained in hydrated conditions at around $4^{\circ} \mathrm{C}$. In case of inhibition based biosensors $\mathrm{IC}_{50}$ of the tested inhibitors has to be determined at different time periods following enzyme immobilization to see if the obtained results are not affected by the loss of enzyme activity.

Biosensors have some major advantages over traditional analytical methods, which will certainly lead to their even more pronounced use in the pharmaceutical and biomedical field in the near future: they are prone to miniaturization which is of great importance because biological samples are available in small amounts and tissue damage must be minimized in case of in-vivo monitoring, the detection of the key substrate is very often made without prior separation, their sensitivity is usually in the order of $\mathrm{ng} / \mathrm{ml}$, they have a high selectivity, sometimes even specificity, they are characterized by short response times and quickness of data collection, they are easy to use (Castillo et al, 2004) and they have a high benefit/cost ratio. 


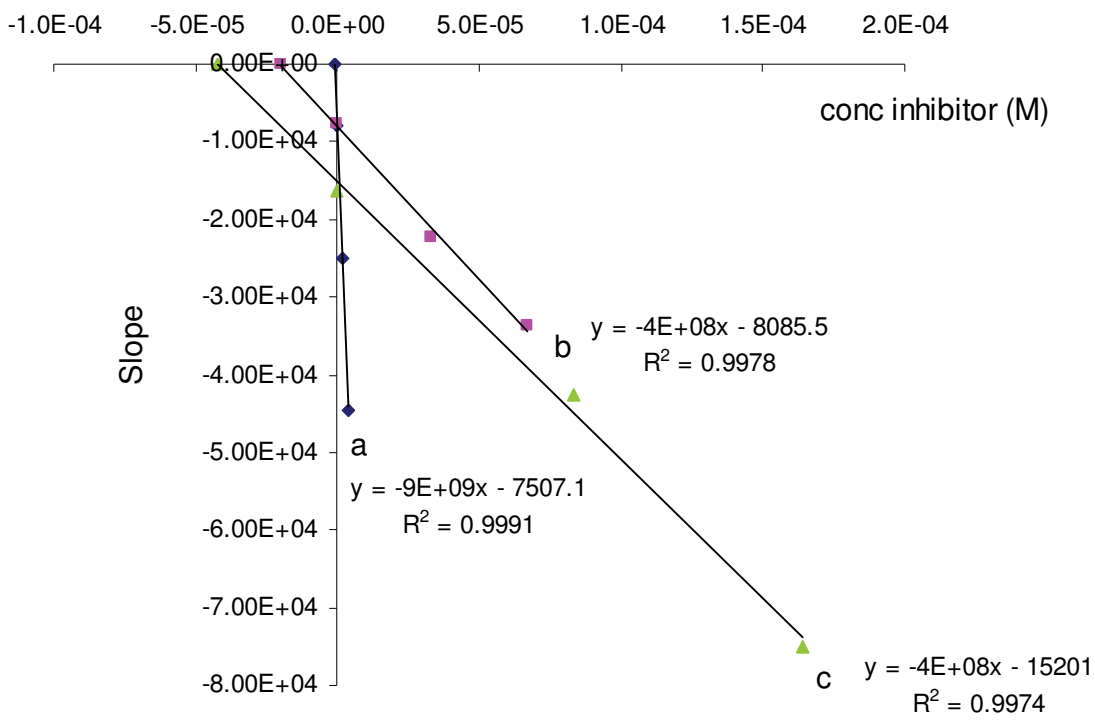

Fig. 4. Tyrosinase based biosensor data: slope of Fig. 3 data vs [In]. a. Kojic acid, b. Benzoic acid, c. Azelaic acid, 0.1M phosphate buffer pH 6.5, Eapp $-100 \mathrm{mV}, 10 \mu \mathrm{L}$ of a $1.25 \mathrm{mg} / \mathrm{mL}$ tyrosinase-NMPS suspension deposited onto the mCPE (Sima et al., 2011)

However, many enzyme-based amperometric biosensors described in the recent literature still display a few drawbacks when compared to other analytical methods. The most difficult problems to overcome for biosensors are: the low reproducibility of the response and the reduced stability due to the fact that the enzymes, removed from their natural environment, tend to rapidly loose their activity and thus limit the lifetime of the sensor, the electrochemical interferences in complex sample matrices and the biocompatibility and biofouling in case of in-vivo measurements (Castillo et al, 2004). Even if they do present some drawbacks these devices can be very efficacious used for adequate analysis. Moreover these disadvantages can be limited and the performances can be optimized by an adequate immobilization method of the biocomponent at the transducer surface.

While the concept of biosensors is simple, their commercialization is far from being simple. A lot of such devices are at scientific stage and only a few of the innovative ideas described in the scientific literature have reached the marketplace and they are only limited applied in clinical practice, as for example the well known glucose portable analyzer for home diagnostic (Wang, 1999); so still more efforts need to be undertaken.

\section{Electrochemical sensors for health applications}

\subsection{Pharmaceutical analysis}

The need for new sensitive devices allowing the simultaneous detection of several drugs showed a steadily increasing trend in the pharmaceutical research. Some examples of electroanalytical methods applied to ascorbic acid (Săndulescu et al, 2000; Marian et al., 2000), phenotiazines (Săndulescu et al, 2000; Blankert et al., 2005), vitamine B1 (Marian et al., 2001; Bonciocat et al., 2003), effervescent solid dosage forms (Săndulescu et al, 2000), benzodiazepines (Bănică et al., 2007), colchicine (Bodoki et al., 2007; Bodoki et al., 2007) and 
paracetamol (Yu et al., 2006; Sima et al., 2008; Sima et al., 2010) were published in the last decade.

The electrochemical behaviour of some pharmaceuticals (caffeine, aminophylline, teophylline, Fig. 5) was investigated by cyclic voltammetry (CV), square-wave voltammetry (SWV) and differential pulse voltammetry (DPV), on different electrode materials: glassy carbon in native and electrochemically activated form, bare or 1,4-benzoquinone modified carbon paste. (Câmpean et al., 2011)

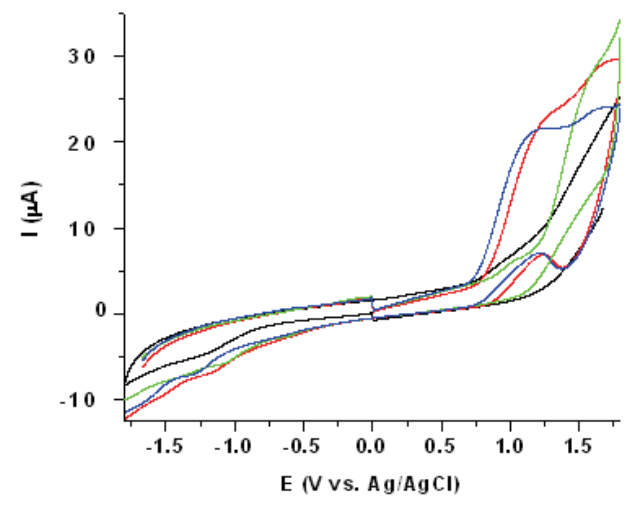

(A)

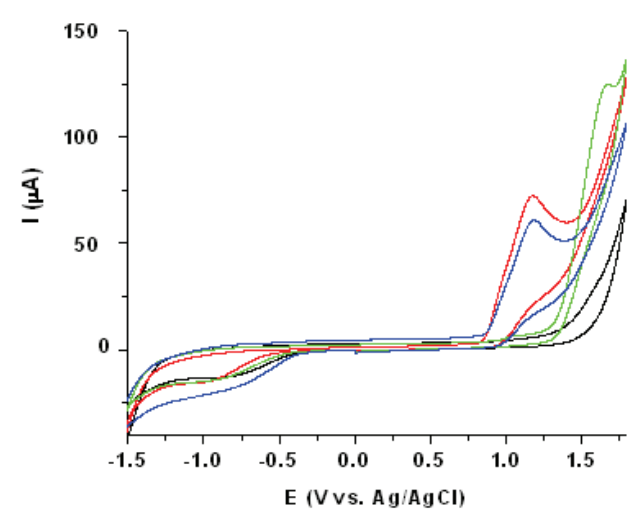

(B)

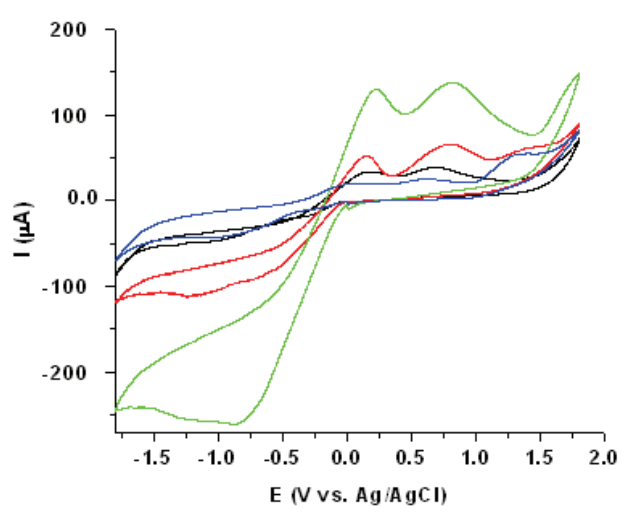

(C)

Fig. 5. Cyclic voltammograms of 10-3 $\mathrm{M}$ aminophylline (red line), caffeine (green line) and theophylline (blue line) solutions in Britton-Robinson buffer at $\mathrm{pH} 4$ (black line), on: (A) glassy carbon electrode; (B) carbon paste electrode and (C) 1,4-benzoquinine modified carbon paste electrode (Reference electrode $\mathrm{Ag} / \mathrm{AgCl},(3 \mathrm{M} \mathrm{KCl})$; auxilliary electrode $\mathrm{Pt}$ wire; scan rate $0.1 \mathrm{~V} \mathrm{~s}^{-1} ; 20^{\circ} \mathrm{C}$ )

The preliminary studies performed on traditional electrodes were extended on carbon based screen-printed electrodes (Fig. 6), simple and modified with multi-wall carbon nanotubes or cobalt-phtalocyanine. (Câmpean et al., 2011) 


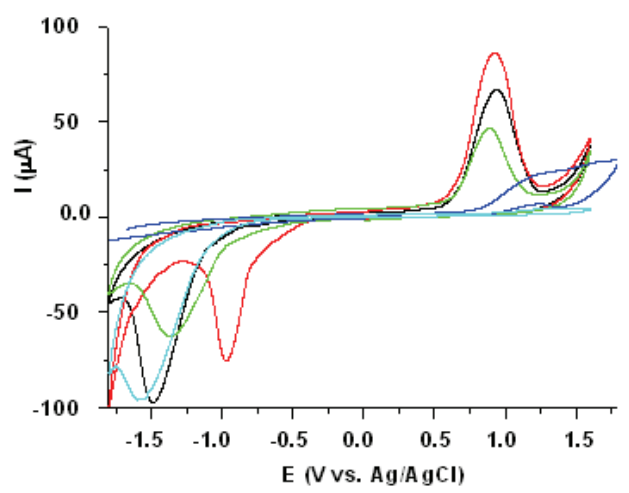

(A)

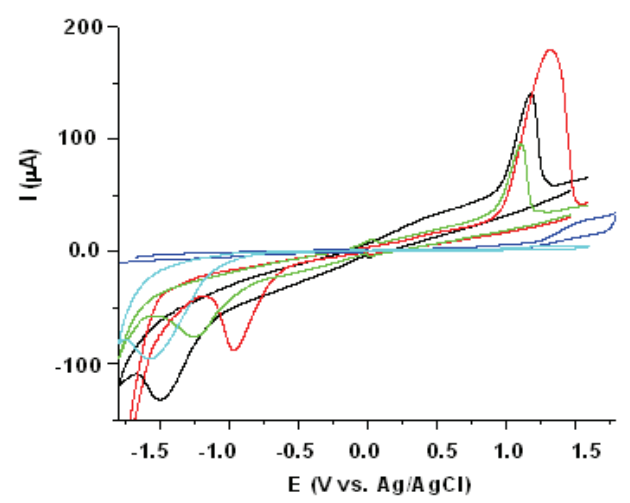

(B)

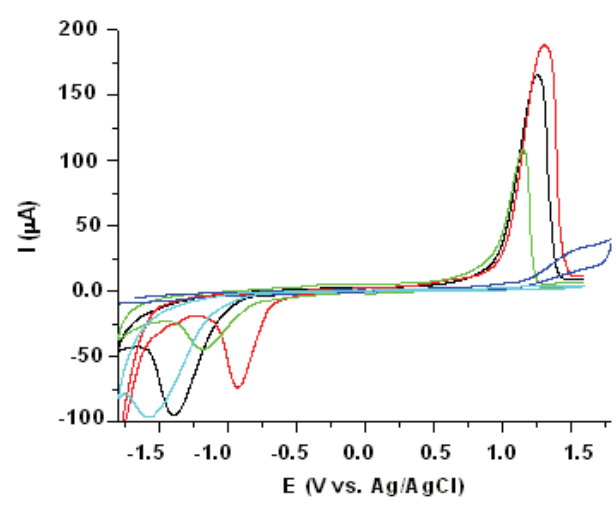

(C)

Fig. 6. Cyclic voltammograms obtained on screen-printed electrodes type: DS 110 with graphite (black line); DS 410 with graphite and cobalt phthalocyanine (red line); DS 110 with graphite modified with multiwall carbon nanotubes (green line); compared with the voltammograms obtained on glassy carbon electrode (blue line); recorded for $10^{-3} \mathrm{M}$ : (A) aminophylline, (B) caffeine, (C) theophylline solutions in Britton-Robinson buffer at $\mathrm{pH} 4$ (cyan line) (Reference electrode Ag; auxiliary electrode graphite; scan rate $0.1 \mathrm{~V} \mathrm{~s}^{-1} ; 20^{\circ} \mathrm{C}$ )

A horseradish peroxidase (HRP) - Zirconium alcoxide porous gel film biosensor for acetaminophen determination was obtained by enzyme immobilization on glassy carbon and carbon based screen-printed electrodes and has been reported by V. Sima et al. (2008). The investigated zirconium alkoxide porous gel film represents an interesting way for biocomponent immobilization onto the glassy carbon electrode, conferring in the mean time a hydrated environment for the enzyme.

Two different zirconium alcoxide gels have been prepared, starting from different amounts of zirconium salt: $0.25 \mathrm{M}$ and $0.4 \mathrm{M}$ alcoholic solutions by refluxing for 2 hours at $90^{\circ} \mathrm{C}$ then allowed to cool at room temperature. $6.5 \mu \mathrm{l}$ porous $\mathrm{Zr}$ alcoxide gel were added to $5 \mathrm{mg}$ polyethyleneimine (PEI) in hydroalcoholic media. Equal amounts of the 0.03 and 0.06 $\mathrm{mg} / \mathrm{mL}$ HRP enzyme solution and the above described alkoxide gel were mixed for 15 
minutes and $20 \mu \mathrm{l}$ of the resulting mixture was deposited on the glassy electrode surface and left over night at $4^{\circ} \mathrm{C}$ for drying. For another 24 hours it was left at $4^{\circ} \mathrm{C}$ in $5 \mathrm{ml}$ phosphate buffer for hydratation.

The enzymatically generated reactive oxidized species of acetaminophen were electrochemically reduced and the amperometric signal was recorded. (Fig. 11)

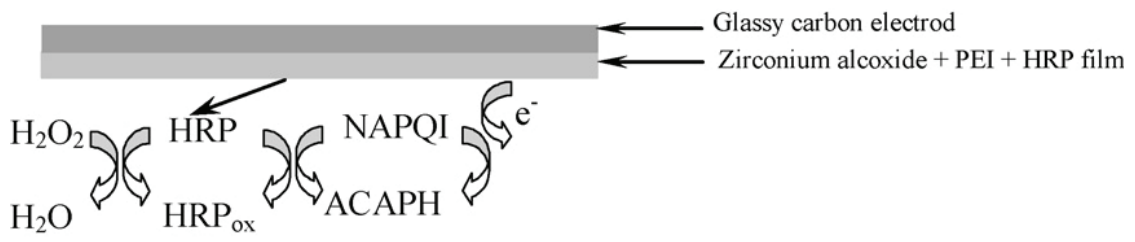

Fig. 11. The mechanism of biocatalytic peroxidation of acetaminophen (ACAPH) into N-acetylparabenzoquinonimine (NAPQI) by HRP immobilized at the surface of the electrode

The cyclic voltammetric assays showed that the zirconium alcoxide porous gel was a biocompatible material, capable to preserve the enzyme's bioactivity. The $\mathrm{ZrO}_{2}$-PEI thin film exhibited good electrocatalytical and electroanalytical response towards acetaminophen and $\mathrm{H}_{2} \mathrm{O}_{2}$. The decrease of the oxidation current until about $50 \%$ between the electrodes modified with a film of PEI and a film containing $\mathrm{Zr}$ alcoxide shows the improved conductive properties of the alcoxide film.

Electrochemical differences were observed also between a hydrated and a dry film. To explain this behavior microscopic studies were conducted. Fig. 12 shows surface topography images of dry (a) and hydrated $\mathrm{ZrO}_{2}$-PEI thin films (b), respectively. As shown in Fig. 12, particle size was in the ranges of micrometers. The surface topography changes considerably in the case of hydrated $\mathrm{ZrO}_{2}$-PEI thin film (Fig. 12b). The dry film presented cracks and pores, whereas the hydrated film had a more homogenous structure.

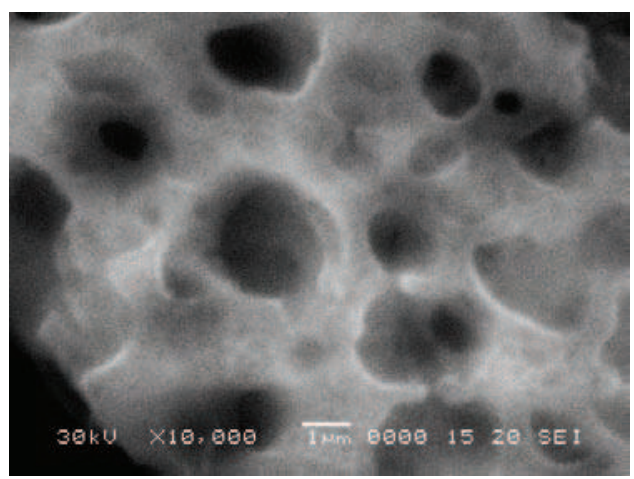

a)

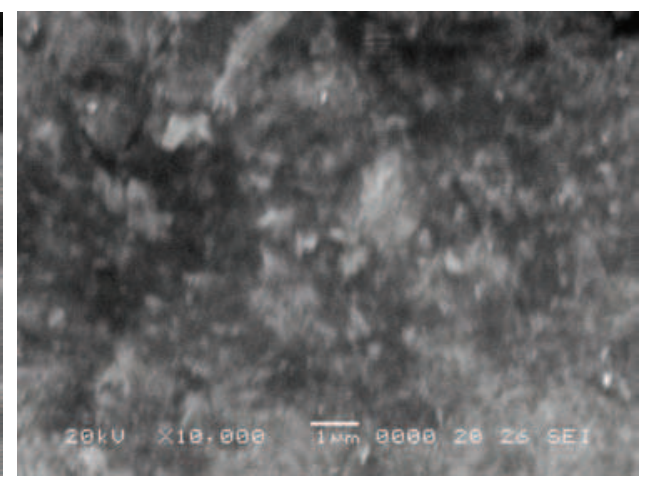

b)

Fig. 12. Electron microscopy images of the dry (a) and hydrated film (b)

The biosensor was applied to the acetaminophen assay in drug formulation, Perdolan ${ }^{\circledR}$ and a generic solid dosage form made in our department. The standard addition method was used. A linear trend of current versus acetaminophen concentration was found for 
concentrations between $2.0 \cdot 10^{-5} \mathrm{M}$ and $1.6 \cdot 10^{-4} \mathrm{M}\left(\mathrm{R}^{2}=0.9996\right.$, RSD of slope $\left.=20 \%, \mathrm{n}=5\right)$ with a LOQ of $1.17 \cdot 10^{-7} \mathrm{M}$.

Another biosensor configuration based on the immobilization of horseradish peroxidase (HRP) within a zirconium alcoxide film on screen-printed electrodes (SPE) for the analysis of acetaminophen from Perdolan ${ }^{\circledR}$ tablets was also developed (Sima et al., 2010). The biosensor's operation mode was also based on monitoring the amperometric signal produced by the electrochemical reduction of the enzymatically generated electroactive oxidized species of acetaminophen in the presence of hydrogen peroxide.

In the case of SPEs modified with $10 \mu \mathrm{L}$ film without HRP ( $5 \mathrm{mg}$ PEI, $125 \mu \mathrm{L}$ ethanol and 120 $\mu \mathrm{L}$ distilled water), in a control solution (phosphate buffer $0.1 \mathrm{M} \mathrm{pH=7.4)} \mathrm{at} 0.57 \mathrm{~V} \mathrm{vs}$. Ag pseudoreference, an irreversible oxidation peak which becomes much smaller at the second cycle was observed. The compound formed during the first cycle was not further reduced, thus the oxidation current at the second cycle was much smaller. It is not clear which compound was oxidized, or whether this compound was part of the film, or an impurity in the film. The second cycle, which was stable for multiple scans, was taken to be the background level.

A higher background current in the control solution was observed in the case of film modified SPEs, probably due to specific interactions between the zirconium and the electroconductive graphite-based ink used to print the SPE working electrode.

After the deposition of the zirconium alcoxide-PEI film onto the glassy carbon working electrode, the electrochemical signal of paracetamol decreases, as a consequence of electroactive surface blockage of the of the working electrode by the PEI (Fig. 13).

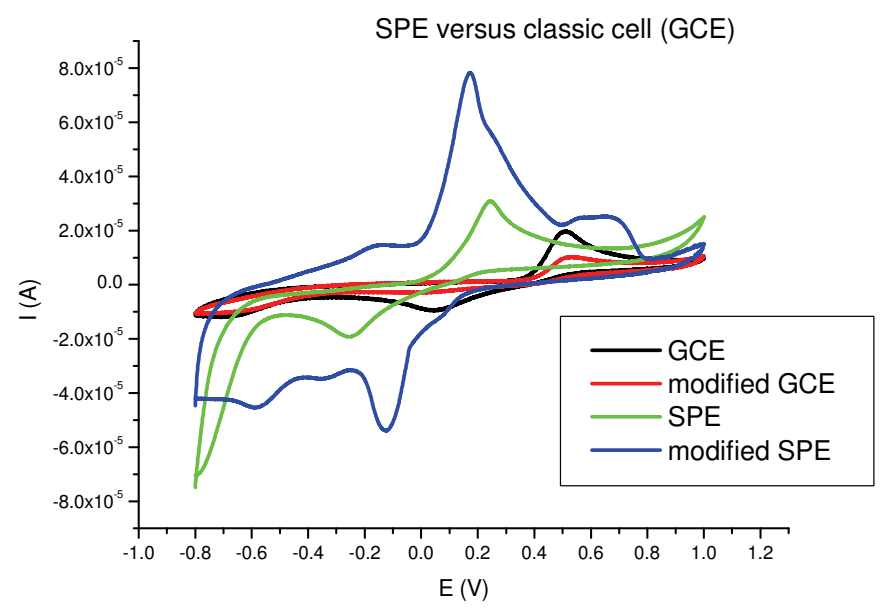

Fig. 13. Cyclic voltammograms for unmodified and $20 \mu \mathrm{L}$ non enzymatic film (zirconium alcoxide-PEI gel) modified GC and SPE working electrodes in paracetamol $6.25 \cdot 10^{-4} \mathrm{M}, 0.1$ $\mathrm{M}$ phosphate buffer $\mathrm{pH}=7.4$ - cyclic voltammetry, applied potential between $-0.8 \mathrm{~V}$ and 1.0 $\mathrm{V}$, scan rate $100 \mathrm{mV} \mathrm{s}^{-1}$

After the deposition of the zirconium alcoxide-PEI film onto the surface of the SPE working electrode, the electrochemical signal of paracetamol increased, probably due to the catalytic activity of the zirconium alcoxide. Another difference between the unmodified and the film- 
modified SPE was the peak separation voltage $(\Delta E \mathrm{E})$ : in the case of the unmodified SPE, $\Delta \mathrm{Ep}$ was $0.5 \mathrm{~V}$, and in the case of the modified SPE, $\Delta \mathrm{Ep}$ was $0.29 \mathrm{~V}$ (Fig. 13). The smaller difference between the oxidation and reduction potential in the case of the film-modified SPE demonstrates that the zirconium alcoxide facilitated electron transfer between the analyte and the working electrode.

The sensitivity obtained with the SPE was significantly higher than the one obtained with glassy carbon electrode (GCE). The two experiments were carried out using the same fabrication technique for the entire biosensor (same composition of the enzymatic film) and using the same electrochemical parameters. Even if the electrochemical active surface area of the SPE was larger than that of the GCE, the difference of sensitivity between the two electrodes was much larger than what this difference can account for. This leaded us to believe that the improved sensitivity was due to factors other than the larger active area.

\subsection{Biomedical analysis}

The detection of a large spectrum of biological analytes has been performed during the last decades using inexpensive and sensitive electrochemical methods. The most commonly used electrodes were the carbon based electrodes because of their low cost, good electron transfer kinetics and biocompatibility. Recently, carbon nanotubes (CNTs) have also been incorporated into electrochemical sensors. The CNTs offer unique advantages including enhanced electronic properties, a large edge plane/basal plane ratio, and rapid electrode kinetics. Therefore, CNT-based sensors generally have higher sensitivities, lower limits of detection, and faster electron transfer kinetics than traditional carbon electrodes. To optimize a CNT sensor many variables need to be tested. Electrode performance depends on the synthesis method of the nanotube, CNT surface modification, the attachment method onto the electrode, and the addition of electron mediators. The physical and catalytic properties make CNTs ideal for use in sensors and biosensors. It is known that CNTs display high electrical conductivity, chemical stability, and mechanical strength. There are two main types of CNTs: single-walled CNTs (SWCNTs) and multi-walled carbon nanotubes (MWCNTs). SWCNTs are $\mathrm{sp}^{2}$ hybridized carbon in a hexagonal honeycomb structure that is rolled into hollow tube morphology (Jacobs et al., 2010). MWCNTs are multiple concentric tubes encircling one another. A SWNT consists of a single graphite sheet rolled seamlessly, defining a cylinder of 1-2 nm diameter. Carbon nanotubes can behave as metals or semiconductors depending on the structure, mainly on the diameter and helicity.

Besides the incorporation of protein and antibodies which allowed their direct detection, the incorporation of enzymes onto the surface of the electrode is considered attractive for the direct detection of other non-electroactive biomolecules. The major properties of the enzymes are the specificity and high affinity for the target substrate. The CNTs were added to the enzyme biosensors for their electrocatalytic effect for the glucose or hydrogen peroxide.

In the development of the oxidase-based amperometric biosensors the glucose oxidase plays an important role. The glucose oxidase (GOx) is widely employed in most of the glucose biosensors due to its stability and high selectivity to glucose. The property of GOx with negative charge in neutral $\mathrm{pH}$ solutions also makes it feasible to immobilize GOx onto materials with positive charge by physical adsorption. It is formed by two flavine adenine dinucleotide (FAD) cofactors and catalyzes the oxidation of glucose according to the following reaction (Jacobs et al., 2010): 


$$
\text { Glucose }+\mathrm{O}_{2} \rightarrow \text { Gluconolactone }+\mathrm{H}_{2} \mathrm{O}_{2}
$$

The amount of glucose is proportional to that of the produced $\mathrm{H}_{2} \mathrm{O}_{2}$, by consequence the glucose concentration can be directly determined through measuring the current derived from the electrochemical reaction of $\mathrm{H}_{2} \mathrm{O}_{2}$ (Kong et al., 1009).

The ability of carbon nanotubes (CNT) to promote the electron-transfer reaction of hydrogen peroxide suggests interesting applications of the CNTs for oxidase-based amperometric biosensors (Laschi et al. 2008).

Amperometric biosensors, which combine the bioselectivity of redox enzymes with the inherent sensitivity of amperometric transductions, have proven to be very useful for the detection of glucose.

The glucose biosensor is one of the most studied devices and is widely used as a clinical indicator of diabetes and in the food industry for quality control (Bakker, 2004; Prodromidis \& Karayannis, 2002; Yang et al., 2004; Kong, et al., 2009; Liu et al., 2008). The glucose biosensors represent about $85 \%$ of the entire biosensor market. The considerable research and innovative detection strategies associated with glucose biosensors are justified by the interesting economic prospects. Amperometric glucose oxidase electrodes have played a leading role in the simple one-step blood sugar testing and continuous real time glucose monitoring. (Nenkova et al., 2010).

In the construction of an amperometric biosensor finding an appropriate matrix to immobilize the enzyme and to keep its activity for long-term application is another key issue. Many methods such as covalent binding (X.F. Yang et al., 2006) and cross-linking method have been used to immobilize the GOx onto different supporting materials. Silica gel (Jiang et al., 2006), polymers (Cosnier \& Popescu, 1996), biomaterials (Wu et al., 2004) and their composites have been extensively explored to encapsulate enzymes and microorganism. Even that considerable progress has been made, some challenges still has to be overcome, such as leakage of enzyme from the matrix, long and complicated procedures for matrix preparation and short life time (Chang et al., 2010). Other examples of enzyme immobilization is represented by their inclusion in gels, cross-linked polymers, conductive salts or simply mixing them into carbon paste or carbon-organic polymer hosts. In general, the main requirement of support materials for enzyme immobilization is their adsorption ability and the preservation of the enzyme's catalytic properties during and after the immobilization process. Different polymeric materials have found wide application as enzyme immobilization matrices. In the literature are reported glucose biosensors developed by in situ electropolymerization of different monomers in the presence of glucose oxidase (Cosnier et al., 1999; Cosnier, 1999; Olea et al., 2008; Rubio Retama et al., 2004; Pan et al.; Ramanavicius et al., 2005).

The capture of CNTs in polymeric chains has been found useful for improving their solubility without impairing their physical properties. This strategy, based on wrapping water-soluble linear polymers around the tubes is robust and simple. Another advantage of this noncovalent attachment is that the structure of the nanotube is not altered, thus its mechanical properties remains unaltered. The advantages of dispersing multiwall carbon nanotubes in polyethylenimine for the development of electrochemical sensors for the detection of hydrogen peroxide, using screen-printed graphite-based electrodes as transducers and glucoseoxidase as bioreceptor has been reported (Rubianes \& Rivas, 2007; Laschi et al., 2008). 
An interesting approach was used for the elaboration of a new disposable electrochemical sensor for the detection of hydrogen peroxide, using screen-printed carbon-based electrodes (SPCEs) modified with multi-walled carbon nanotubes (MWCNs) dispersed in a polyethylenimine (PEI) mixture. The modified sensors showed an excellent electrocatalytic activity towards the analyte, with respect to the high overvoltage characterizing unmodified screen-printed sensors. The composition of the PEI/MWCNT dispersion was optimized in order to improve the sensitivity and reproducibility.

Different compositions of PEI/MWCNT suspension were tested. The sensitivity of the sensor (estimated on the basis of the slope of the calibration curve obtained for hydrogen peroxide) was used as a parameter to compare the performance of sensors obtained with different coatings. Each composition was analyzed in triplicate with the same sensor and the average sensitivity values lay in the range of $3.33-101.23 \mu \mathrm{AmM}^{-1}$. Not only the amounts of PEI and MWCNT were varied, but also the volume of the dispersion deposited onto the working electrode. The linear trend was always maintained, but an increase in sensitivity from 3.33 to $30.32 \mu \mathrm{AmM}^{-1}$ was achieved by doubling the deposited volume from 5 to $10 \mu \mathrm{l}$. The optimized sensor showed good reproducibility $(10 \%$ RSD calculated on three experiments repeated on the same electrode), whereas a reproducibility of $15 \%$ as RSD was calculated on electrodes from different preparations.

The amperometric response of a PEI/MWCNT/GOD modified screen-printed electrode was studied at $+700 \mathrm{mV}$ in $0.05 \mathrm{M}$ phosphate buffer solution with $\mathrm{pH}$ 7.4. During successive additions of $0.5 \mathrm{mM}$ glucose, a well-defined current response was observed. For each addition of glucose, a sharp rise in the current was observed, while no response was recorded in analogous measurements at the bare PEI/MWCNT electrode. The calibration plot was linear over a wide concentration range, $0.5-3.0 \mathrm{mM}$. The data interpolation in this concentration range had a slope of $22.18 \mu \mathrm{AmM}^{-1}$, with a correlation coefficient of 0.998 .

Preliminary experiments carried out using glucose oxidase (GOD) as biorecognition element gave rise to promising results indicating that these new devices may represent interesting components for biosensor construction (Laschi et al., 2008).

\subsection{Biorecognition and drug - receptor interaction studies}

Molecular recognition or biorecognition is the essence of all biological interactions. These interactions generally involve noncovalent bonding (i.e. ionic, hydrogen bonding, hydrophobic interactions), where additionally shape complementarity plays an important role. During the last few years screen printed electrodes proved to be valuable tools in the study and development of new bioselectors. Their great versatility lies in the wide range of ways in which the electrodes may be modified, either by altering the composition of the printing inks or by depositing thin films of purposely designed supramolecular structures on the manufactured electrodes (Dominguez Renedo et al., 2007). Films of biomolecules have been used to tailor the properties of interfaces, providing solid surfaces to catalyze enzyme reactions, enabling fundamental biochemical and biophysical studies and nonetheless, serve in biosensors as biorecognition and biomimetic elements (Rusling, 2010). The application field of such sensors is overwhelmingly broad, but the ones concerning clinical chemistry and analysis, drug and genetic testing stand out in particular. Electrochemical biosensors for the study of DNA interaction, hybridization and damage has become one of the most vibrant and dynamic areas of physical sciences and sensor engineering (Paleček et al., 1998; Teles \& Fonseca, 2008). The molecule of DNA as carrier of 
genetic information is a major target for drug interaction. This phenomenon may interfere with transcription (gene expression and protein synthesis) and DNA replication, representing a fundamental issue in medical science. The evaluation of any interaction with DNA using biosensors helps to predict unwanted toxic side-effects and prevent DNA damage caused by therapeutic drugs.

Colchicine is a protoalkaloid, used as a specific antiinflammatory agent in acute attacks of gout by inhibiting the migration of leucocytes to inflammatory areas, thus interrupting the inflammatory response that sustains the acute attack. The drug also presents an antimitotic action, arresting dividing cells in metaphase by preventing normal function of mitotic spindle.

By studying colchicine's electrochemical signal obtained on graphite based screen printed electrode the influence of several bioselectors (calf thymus DNA, $\beta$-tubulin and bovine serum albumine) was investigated.

A disposable biosensor based on the immobilization of double - stranded calf thymus DNA (type XV, Sigma, Milan, Italy) was used to assess its possible interaction with colchicine.

The detailed protocol of production and use of the DNA biosensor was described earlier (Bagni et al., 2006), where the oxidation peak of guanine is used as the transduction signal to recognize DNA interacting agents. As the result of a specific or non-specific interaction (covalent binding, electrostatic interaction with the negatively charged nucleic acid sugar phosphate, hydrogen and/or van der Waals bonds) of the double stranded calf thymus DNA with a genotoxic agent, a decrease of the guanine peak (measured by square-wave voltammetry - SWV) is detected. Measurement of the target analyte with the DNA modified screen-printed electrode includes four main steps: (i) electrochemical conditioning of the electrode surface in order to oxidize the graphite impurities and to obtain a more hydrophilic surface to favor DNA immobilization, (ii) calf thymus ds-DNA immobilization, (iii) interaction with the colchicine solution and (iii) electrode surface interrogation. In details, the experimental procedure was the following (Fig. 14) (Bodoki et al., 2009):

a. Electrode pre-treatment: applying potential of $+1.6 \mathrm{~V}$ (vs. Ag-SPE pseudo-reference) for $120 \mathrm{~s}$ and $+1.8 \mathrm{~V}$ (vs. Ag-SPE) for $60 \mathrm{~s}$; electrode in $5 \mathrm{~mL}$ of $0.25 \mathrm{M}$ acetate buffer, containing $10 \mathrm{mM} \mathrm{KCl}(\mathrm{pH}=4.75)$, under stirred conditions;

b. DNA-immobilization: electrode dipped in a solution of $50 \mathrm{ppm}$ calf thymus ds-DNA in $0.25 \mathrm{M}$ acetate buffer containing $10 \mathrm{mM} \mathrm{KCl}$, applying a potential of $+0.5 \mathrm{~V}$ (vs. Ag-SPE) for 5 minutes, under stirred conditions;

c. Blank or sample interaction: $10 \mathrm{uL}$ of buffer or sample solution on the electrode's surface for 2 minutes;

d. Measurement: SWV scan in order to evaluate the oxidation of guanine residues on the electrode surface. The height of the guanine peak (at $+0.95 \mathrm{~V}$ vs. Ag-SPE) was measured in $0.25 \mathrm{M}$ acetate buffer, containing $10 \mathrm{mM} \mathrm{KCl}$; SWV parameters: $\mathrm{E}_{\mathrm{i}}+0.2 \mathrm{~V}, \mathrm{E}_{\mathrm{f}}+1.45 \mathrm{~V}$, $\mathrm{v}=200 \mathrm{~Hz}, \mathrm{E}_{\text {step }} 15 \mathrm{mV}, \mathrm{E}_{\text {amplitude }} 40 \mathrm{mV}$.

Assessing the oxidation peak of guanine residues compared with the baseline, there is no current decrease, nor any potential shift, after the exposure to colchicine of the DNA biosensor, indicating an apparent lack of interaction.

However, at fairly higher concentrations of DNA $\left(100-220 \mu \mathrm{g} \mathrm{L}^{-1}\right)$, based on the decrease of colchicine's peak current obtained on glassy carbon electrode by differential pulse voltammetry, the formation of DNA-colchicine complex was demonstrated with a combination ratio of 1:2 (Hui et al., 2011). 


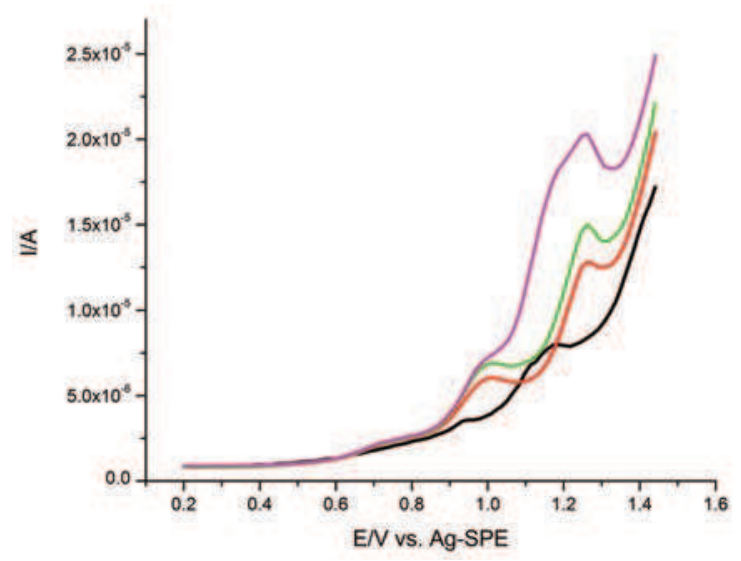

Fig. 14. Square wave voltammograms using screen-printed DNA biosensor. (black) without DNA immobilization, blank of colchicine $\left(2.6 \cdot 10^{-5} \mathrm{M}\right)$; (red) with DNA immobilization, no colchicine; (green) with DNA immobilization, with colchicine $\left(2.6 \cdot 10^{-5} \mathrm{M}\right)$; (magenta) with DNA immobilization, with higher concentration of colchicine $\left(2 \cdot 6 \cdot 10^{-4} \mathrm{M}\right)$.

Colchicine acts as an antimitotic agent by inhibiting microtubule polymerization by binding with high affinity to tubulin, a negatively charged protein $(\sim 120 \mathrm{kDa})$, formed by two globular polipeptidic subunits (a-tubulin and $\beta$-tubulin). Tubulin is one of the main constituents of the microtubules of the division spindle. Inhibitors of tubulin polymerization interacting at the colchicine binding site are potential anticancer agents, thus colchicinetubulin interaction was very extensively studied in the last twenty years.

It has been demonstrated that the binding to the tubulin dimmer ( $\alpha$ - and $\beta$-subunits) is slow and poorly reversible due to conformational changes in the protein's structure, whereas binding to $\beta$-tubulin monomers is reversible and 3-4 times faster (Banerjee et al., 1997). Therefore, the screen-printed electrodes were modified applying $5 \mu \mathrm{L}$ of $25 \mathrm{ng} \mathrm{mL}^{-1} \beta-$ tubulin in $10 \mathrm{mM}$ HEPES buffer on the electrode's surface, followed by drying at room temperature.

Due to the specific colchicine- $\beta$-tubulin interaction, an anodic shift of colchicine's oxidation peak can be observed ( $+1.06 \mathrm{~V}$ vs. Ag-SPE) accompanied by a decrease of the anodic current (Fig. 15). This decrease is not due to the electrode surface blockage by the deposited protein, since the same potential shift and current decrease is observed when $\beta$-tubulin is directly added in the voltammetric cell.

The literature describes also the formation of colchicine - bovine serum albumin complex, stabilized by van der Waals interactions and hydrogen bonds (Hu et al., 2005). Therefore, this interaction's influence on the electrochemical behavior of colchicine was also investigated using bovine serum albumin (BSA) surface modified SPE's.

A similar potential shift and anodic current decrease as in the case of $\beta$-tubulin was observed when the surface of screen-printed electrode was modified applying $7 \mu \mathrm{L}$ of $0.025 \% \mathrm{~m} / \mathrm{v}$ BSA followed by drying at room temperature or when the albumin was added to the bulk solution of the voltammetric cell. These data might be explained by the strong interaction of colchicine with the BSA determining a less favorable conformation of the colchicine molecule for the heterogeneous electron transfer. 


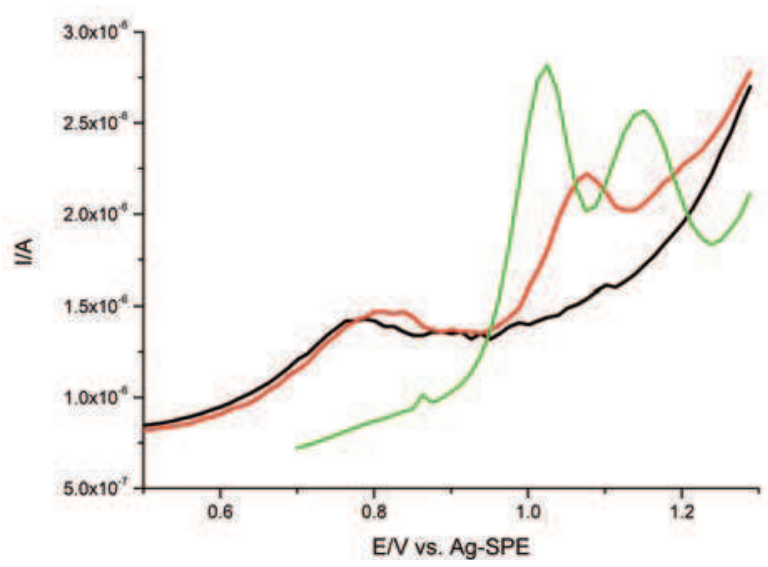

Fig. 15. Anodic differential pulse voltammograms using screen-printed electrodes modified with $\beta$-tubulin. (green) unmodified screen-printed electrode, $853.98 \mathrm{ng} / \mathrm{mL}$ colchicine in $\mathrm{H}_{3} \mathrm{PO}_{4} / \mathrm{HClO}_{4} 0.01 \mathrm{M}$; (black) $\beta$-tubulin modified screen-printed electrode, blank anodic DPV run in $\mathrm{H}_{3} \mathrm{PO}_{4} / \mathrm{HClO}_{4}$ 0.01M; (red) $\beta$-tubulin modified screen-printed electrode, 853.98 $\mathrm{ng} / \mathrm{mL}$ colchicine in $\mathrm{H}_{3} \mathrm{PO}_{4} / \mathrm{HClO}_{4} 0.01 \mathrm{M}$.

\section{Electrochemical sensors for environmental applications}

\subsection{Heavy metal detection and removal}

The importance of sensor development for the detection of pollutants from environmental samples lies in their large field of application. The detection and the removal of the heavy metals show a great interest because they are very persistent in the environment, generally without being decomposed by the bacteria, they are toxic even in traces and their accumulation in the living cells can cause severe pathologies.

A flow electroanalytical system for trace analysis, using modified graphite felt as working electrode was reported (Cristea et al., 2009). The graphite felt was chosen because of its numerous advantages like great specific surface, lack of toxicity, possibility to be used in flow systems, accessibility, low cost and ease of use (Cristea et al., 2005a; Cristea et al., $2005 \mathrm{~b})$. The immobilization of 1,8 diamino 3,6 dioxaoctane as receptor has been studied in order to increase the performances of the sensor in terms of selectivity (Geneste \& Moinet, 2004; Geneste \& Moinet, 2005; Nasraoui et al., 2009). The covalent attachment of the receptor at the surface of the porous electrode has been made by anodic oxidation in a cross-flow cell. The molecular structure of the receptor allows its attachment through either one or both amino groups leading to the formation of a cycle.

The modification of the graphite felt electrode was made by using a ligand previously tested in homogenous medium in reaction with some metallic ions (Loris et al., 1999). The literature reports the stability constants of the complexes obtained with several metallic ions (i.e. $\mathrm{Pb}(\mathrm{II}), \mathrm{Cu}(\mathrm{II}), \mathrm{Ni}(\mathrm{II}), \mathrm{Cd}(\mathrm{II}), \mathrm{Zn}(\mathrm{II}), \mathrm{Hg}(\mathrm{II})$ ).

Graphite felt used as electrode in a flow cell was modified by anodic oxidation with 1,8diamino-3,6-dioxaoctane in phosphate buffer at $\mathrm{pH}$ 7,2. Electrochemical and other experiments showed the double insertion of the compound by two amino groups giving a macrocycle at the surface of the graphite. In order to control the efficiency and the mode of 
grafting, part of the modified graphite was treated with a specific reagent for amino groups $\left(4-\mathrm{O}_{2} \mathrm{NC}_{6} \mathrm{H}_{4} \mathrm{COCl}\right)$ bearing an electroactive nitro group that can be electrochemically detected after reaction. Grafting according reaction 4 was not detected; unfortunately, grafting according $\mathbf{5}$ was not detected too. In this last case, a steric effect can be invoked due to the surface of graphite fibber for explaining the non reactivity of the acyl chloride with the secondary amino groups bonded on the graphite:

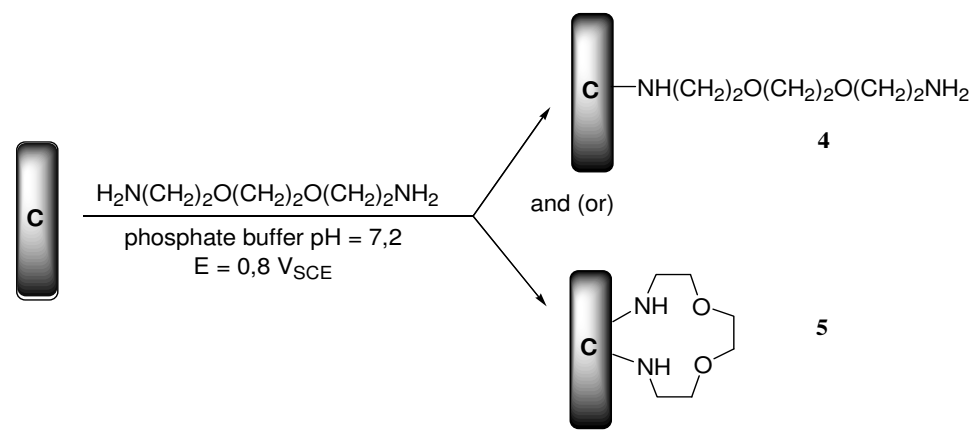

Different techniques were developed during the study, which allowed the grafting of the compound of interest in three distinct ways: predominantly as a cycle, predominantly as a one-end-attached molecule and as a mixture of the first two.

A formation mechanism of the macrocycle between the 1,8-diamino-3,6-dioxaoctane and the graphite felt was imagined. The proposed mechanism involves the two amino groups susceptible to oxidation at the same potential. It is probably a simultaneous radical attack of a double bond undergoing until the saturation of the surface sites. At this point, the oxidation driving force will disappear because of the lack of the radical coupling with the graphite and the oxidation of the two amino groups will become more difficult. It could be assumed that the macrocycle will be formed with two vicinal atoms of carbon:

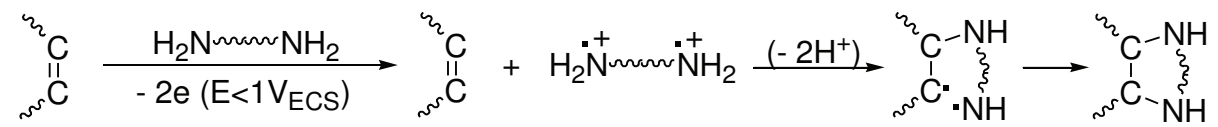

The detection of the heavy metals (especially lead) has been performed in two steps: the preconcentration by complexation of the analyte by percolating the sample solution through the modified electrode and its analysis by linear sweep stripping voltammetry. By studying the influence of different experimental parameters (receptor's immobilization type, time of percolation, etc.) the best electrochemical signal for lead was obtained when the receptor was bonded to the surface of the electrode at only one end.

However, the electroanalytical verification of grafting according reaction $\mathbf{5}$ was obtained by $\mathrm{Pb}$ (II) trapping by ultrasonication, from a solution of $\mathrm{Pb}\left(\mathrm{NO}_{3}\right)_{2}\left(5 \cdot 10^{-2} \mathrm{M}\right)$, with prior rinsing with water:

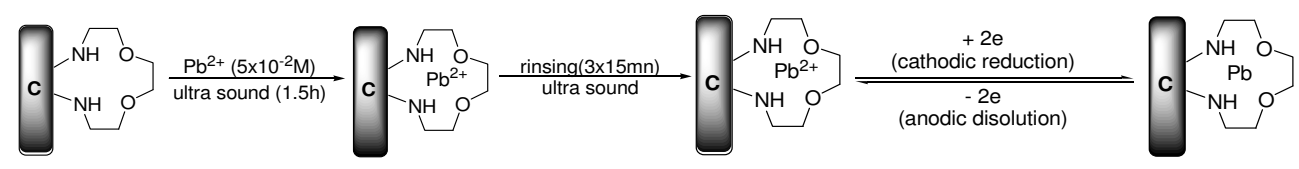


The cyclic voltammogram using an electrode of $1 \mathrm{~cm}$ diameter confirms the presence of crypted $\mathrm{Pb}(\mathrm{II})$ which after the cathodic reduction shows a characteristic anodic peak denoting the dissolution of lead (Fig. 16).

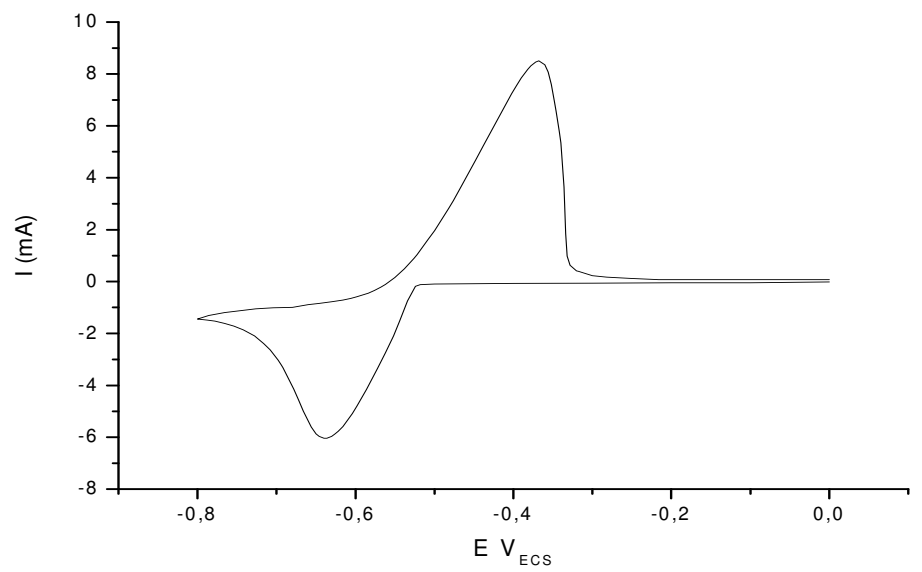

Fig. 16. Cyclic voltamogram on a modified graphite felt porous electrode immersed for $20 \mathrm{~h}$ $5 \cdot 10^{-2} \mathrm{M} \mathrm{Pb}\left(\mathrm{NO}_{3}\right)_{2}$; supporting electrolyte $0.1 \mathrm{M} \mathrm{LiClO}_{4}$, scan rate $20 \mathrm{mVs}^{-1}$.

The reaction rate between the 1,8-diamino-3,6-dioxaoctane and the lead was also investigated, which turns out to be strongly time dependent. It can be concluded that the complexation reaction between the grafted ligand and the metal ion is relatively slow. The results show that that the complete trapping of the metallic ion is done after 3 hours at a flow rate of $0.6 \mathrm{~mL} / \mathrm{min}$ of the metal ion solution. The signal decreases with the increase of the flow rate to $1.2,2.4$ and $4.8 \mathrm{~mL} / \mathrm{min}$ for a percolation time of 30 minutes.

The trapping of other five heavy metals ions were investigated using the grafted porous graphite felt electrode. The obtained limits of detection expressed as concentration in $\mathrm{mol} / \mathrm{cm}^{3}$ of graphite felt are $1.6 \cdot 10^{-7}\left(2.6 \cdot 10^{-10}\right)$ for $\mathrm{Pb}^{2+}, 2 \cdot 10^{-8}\left(3.3 \cdot 10^{-11}\right)$ for $\mathrm{Ni}^{2+}, 1.2 \cdot 10^{-8}$ $\left(2 \cdot 10^{-11}\right)$ for $\mathrm{Cd}^{2+}, 4.5 \cdot 10^{-9}\left(7.4 \cdot 10^{-12}\right)$ for $\mathrm{Zn}^{2+}$ and $3.9 \cdot 10^{-9}\left(6.4 \cdot 10^{-12}\right)$ for $\mathrm{Cu}^{2+}$.

Other ligands were studied in order to obtain new electrode materials for the removal of the heavy metal ions from aqueous solutions. The covalent immobilization of cyclam on the graphite felt was carried out via a previously attached amino acid linker and the resulting sensor's performance for heavy metals detection was studied. The cyclam-modified electrode showed ability to detect $\mathrm{Pb}$ (II) ions without the interference of $\mathrm{Cu}$ (II) with a limit of detection down to $5 \cdot 10^{-8} \mathrm{~mol} \mathrm{~L}^{-1}$. Its behavior exhibits several differences compared with the unmodified graphite felt: the influence of the flow rate on the complexation reaction and an improved selectivity for $\mathrm{Pb}$ (II) over $\mathrm{Zn}$ (II) (Nasraoui et al., 2010).

Another modified graphite felt electrode was obtained by using the carbamoyl-armed macrocycles which exhibit a good selectivity for $\mathrm{Pb}$ (II) ions. A flow-through electrochemical sensor was prepared by covalent attachment of 1,4,8-tri(carbamoylmethyl) hydroiodide (TETRAM) on a graphite felt electrode. This new sensor exhibits higher selectivity than the cyclam-modified electrode for $\mathrm{Pb}(\mathrm{II})$ ions, and does not show interference from other common metal ions. In the optimum analytical conditions a limit of detection of $2.5 \cdot 10^{-8} \mathrm{~mol}$ $\mathrm{L}^{-1}$ was assessed (Nasraoui et al., 2010). 


\subsection{Polyphenols detection}

The phenolic compounds are widely used chemicals turning into toxic pollutants upon their release into the environment. Their environmental occurrence is a result of various production processes of man-made materials such as plastics, dyes, pesticides, paper and petrochemicals.

Phenols are easily absorbed through the skin and mucous membranes of animals and humans, representing a serious environmental issue.

The determination of phenolic compounds is of great importance due to their toxicity and persistency in the environment. Hence, the rapid determination of trace phenolic compounds is of great importance for evaluating the total toxicity of environmental or industrial samples.

One of the most effective and simplest ways to detect the phenolic compounds was by means of amperometric biosensors based on polyphenol oxidase (PPO) (Shan et al., 2007). Polyphenol oxydase (PPO), also called tyrosinase, is a metalloenzyme that contains a binuclear copper active site and catalyses, in the presence of dioxygen, the hydroxylation of monophenols to catechols (monooxygenase activity), which in turn are oxidized to orthoquinone (catecholase activity) (Duckworth \& Coleman, 1970). The phenol biosensor transduction is thus based on the amperometric detection of the enzymatically generated $o$ quinone.

The literature reports several configurations of amperometic biosensors for the detection of polyphenols in environmental and industrial samples. One of this was using for the first time a polycrystalline $\mathrm{BiOx}$ films for the entrapment of biomolecules. This procedure constituted an inexpensive, fast and easy method for the elaboration of enzyme electrodes, by the simple mixing of the colloidal suspension of bismuth oxide with proteins, followed by their deposition on the electrode surface (Shan et al., 2009).

Since PPO catalyses the formation of ortho-quinone and subsequent consumption of dioxygen, the majority of the PPO-based biosensors involves an amperometric transduction based on the quinone reduction. Actually the quinoid products inhibit PPO by undergoing an irreversible binding and passivate the electrode surface via the formation of insulating polymer films. Thus, the majority of the biosensor configurations were based on a mediated reduction of orhto-quinone. Different approaches involve conducting organic salt, metal microparticles and redox mediators immobilization together with the enzyme in a polymer matrix (Cosnier et al., 2001).

Recently, organic phase enzyme electrodes (OPEEs) have attracted considerable interest for their application in environmental and clinical monitoring (Cosnier \& Innocent, 1993; Cosnier \& Popescu, 1996; Mousty et al., 2001).

Electropolymerisation of functionalized polymers is an electrochemical method for the immobilization of biomolecules where the attachment of proteins is performed directly at the polymer-solution interface by chemical grafting or affinity. In comparison to the physical entrapment in polymer films, this approach preserves the catalytic activity and the molecular recognition properties of the immobilized biomolecules.

Several configurations of OPEE are reported in literature being recently reviewed (Lopez et al., 2006).

The use of organic solvents facilitates the detection of non-soluble or poorly water soluble compounds, prevents microbial contamination and may circumvent side reactions leading to enzyme deactivation or electrode fouling. 
The key component of biosensors is the enzyme that is responsible for the specific and sensitive recognition of the analyte. The literature data show that the organic phase enzyme electrodes have been prepared with some proteins that after immobilization preserve functional activity. Some of such biosensors have been successfully applied for real samples working in organic media. Besides tyrosinase other enzymes were also tested in monoenzymatic or in bienzymatic systems. As working electrodes, graphite, glassy carbon, and oxygen gaseous diffusion electrodes were generally used. As for the solvents, acetonitrile, chloroform, dioxane and hexane have been tested (Reviejo et al., 1994). The activity of enzymes in organic media is strongly dependent on their hydration layer, which is essential for their conformational flexibility and for the sensor's stability.

A novel organic phase enzyme electrode (OPEE) via polyphenol oxidase (PPO) entrapment within a hydrophilic polypyrrole film electrogenerated from a new bispyrrolic derivative containing a long hydrophilic spacer was obtained. The pyrrole derivative used in the construction of the biosensor bears two pyrrole groups linked by water solubilizing ethoxy chain:

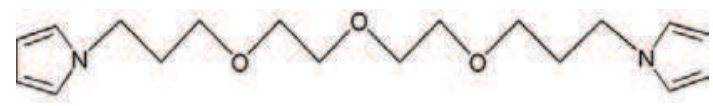

Its electrochemical behavior was investigated by cyclic voltammetry at glassy carbon electrode (GC) in aqueous solution containing $0.1 \mathrm{M} \mathrm{LiClO}_{4}$ as supporting electrolyte. During the oxidative potential scan up to $1.3 \mathrm{~V}$, the cyclic voltammogram of the monomer (5 $\mathrm{mM}$ ) displays an irreversible anodic peak at $1.1 \mathrm{~V}$ due to the oxidation of the pyrrole group into radical cation form. The repetitive potential scanning of the electrode between 0 and $0.8 \mathrm{~V}$ induces the appearance and the growth of a quasi-reversible peak system, located around $0.4 \mathrm{~V}$. This evolution indicates the formation and growth of a polymer film on the glassy carbon surface. The polymerization can also be carried out by controlled potential electrolysis $\left(E_{\mathrm{app}}=0.8 \mathrm{~V}\right.$ versus $\left.\mathrm{Ag} / \mathrm{AgCl}\right)$. It proceeds via a radical cation coupling, involving the release of two electrons and protons per pyrrole unit. Owing to the partly lipophilic character of the long alkyl chain linking the two polymerizable pyrrole groups, the monomer can be adsorbed onto the glassy carbon electrode prior its electropolymerization. This original method, developed in Serge Cosnier's laboratory (Cosnier et al. 2006) for amphiphilic polypyrrole films, allows the control of the monomer and enzyme amounts coated onto the electrode surface and, consequently, of the thickness of the polymer film. The immobilization of PPO was performed by electropolymerization of monomer / enzyme mixture deposited on the surface of glassy carbon electrode following the "adsorption step procedure". For this purpose, a controlled potential of $0.8 \mathrm{~V}$ versus $\mathrm{Ag} / \mathrm{AgCl}$ was applied at glassy carbon electrodes, modified by PPO-monomer coatings, with different ratios of enzyme/monomer of PPO. Since the polymer films were formed from an adsorbed layer, the enzyme loss during the polymerization step can be determined by measuring the enzymatic activity of the surrounding electrolyte. Regardless of the initial amount of PPO in the coating, the quantity of actually immobilized PPO in the polymeric matrix has been estimated at $\sim 99 \%$. The PPO-polymer biosensors were calibrated with catechol, using the $o$-quinone reduction at an applied potential of $-0.2 \mathrm{~V}$ versus $\mathrm{Ag} / \mathrm{AgCl}$. The biosensor's sensitivity to catechol (incorporating $150 \mathrm{nmol}$ monomer and $0.40 \mathrm{mg} \mathrm{PPO}$ ), measured in aqueous buffer solution ( $\mathrm{pH}$ 6.5), was found to be $116 \mathrm{mAM}^{-1} \mathrm{~cm}^{-2}$. In contact with anhydrous chloroform the biosensor still presents a rapid response $\left(t_{90} \sim 30 \mathrm{~s}\right)$ to the 
changes in the catechol concentration. However, irrespective of the enzyme matrix composition, all sensitivities were significantly lower than that measured in the aqueous solution. It is worthy to mention that, the saturation of chloroform with water does not improve the biosensors sensitivity (Fig. 17).

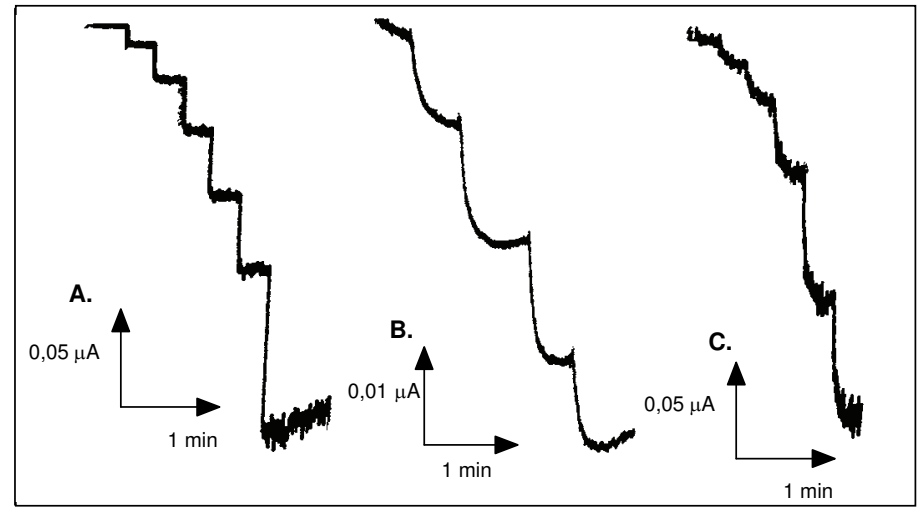

Fig. 17. Amperometric response of the modified electrode with GC-polymer-PPO (150 mmoles monomer and $0.40 \mathrm{mg}$ PPO) in: A. $0.1 \mathrm{M}$ phosphate buffer $\mathrm{pH}=6.5$, successive addition of catechol $\left(10^{-6}<\mathrm{c}<10^{-5} \mathrm{M}\right), \mathrm{B} . \mathrm{CHCl}_{3}, 0.1 \mathrm{M}$ TBAP and phosphate buffer $\mathrm{pH}=6.5$ $0.5 \%(\mathrm{v} / \mathrm{v})$ to successive addition of cathecol $\left(2 \cdot 10^{-4}<\mathrm{c}<8 \cdot 10^{-4} \mathrm{M}\right), \mathrm{C} . \mathrm{CHCl}_{3}$ and $0.1 \mathrm{M}$ TBAP to successive additions of catehcol $\left(6 \cdot 10^{-6}<\mathrm{c}<4 \cdot 10^{-5}\right)$.

Consequently, the strong decrease of the biosensor sensitivity observed in chloroform may be due to the decrease of modified polymer matrix permeability but also to the modification of the enzyme microenvironment within the cross-linked polymer. In order to optimize the biosensor's construction, the effect of the composition of the PPO-monomer coatings on the biosensor's sensitivity was investigated. For the same enzyme loading $(0.20 \mathrm{mg})$, an increase in the monomer's amount does not lead to an improvement of the biosensor sensitivity. As a matter of fact, an increasing polymer film thickness will increase the resistance to diffusion of the substrate from the polymer-solution interface to the enzyme located in proximity of the electrode surface. The optimum composition of the monomer-PPO coating was chosen as $150 \mathrm{nmol}$ of monomer and $0.50 \mathrm{mg}$ PPO. In order to examine the reproducibility of the biosensor's construction, four electrodes were prepared using the same mixture of enzyme and monomer. A relative standard deviation (RSD) of $7.6 \%$ was recorded for the biosensor response to catechol $(5 \mu \mathrm{M})$, this substrate concentration corresponding to the linear part of the calibration curve.

\section{Conclusion}

Electrochemical sensors are very attractive tools in pharmaceutical, biomedical and environmental analysis, combining all the advantages of the electrochemical methods, especially their high sensitivity allowing the detection of very low concentrations of analytes, with the extreme specificity of bioelements (i.e. enzymes, antibodies or DNA). Biosensors offer an extreme flexibility brought on not only by the wide range of biocomponents and composite electrode materials, but also by the inherent conformational 
and operational versatility that facilitates various configurations and geometrical shapes. Last but not least, their analytical value is further enhanced by the possibility of miniaturization (i.e. screen-printed electrodes and the so called "lab-on-a-chip" devices). Nevertheless there are still many drawbacks and problems more or less difficult to solve among which lack of reproducibility, very short service life (especially for enzyme-modified electrodes, either due to the immobilization or the loss of enzymatic activity), biocompatibility in the case of "in vivo" implanted sensors. However, all these issues represent an irresistible challenge for the scientists. It will be the task of this century to ensure the future development and discovery of new electrochemical sensors and their transfer from sophisticated laboratories to end-users from pharmaceutical industry, environmental agencies and hospitals.

\section{References}

Amine, A.; Mohammadi, H.; Bourais, I. \& Palleschi, G. (2006). Enzyme inhibition-based biosensors for food safety and environmental monitoring. Biosensors and Bioelectronics, Vol. 21, No. 8, (February 2006), pp. 1405-1423

Ammam, M. \& Fransaer, J. (2010). Glucose microbiosensor based on glucose oxidase immobilized by AC-EPD: Characteristics and performance in human serum and in blood of critically ill rabbits. Sensors and Actuators B, Vol. 145, No. 1, (March 2010), pp. $46-53$

Andreescu, S. \& Marty, J.L. (2006). Twenty years research in cholinesterase biosensors: From basic research to practical applications. Biomolecular Engineering, Vol. 23, No. 1, (March 2006), pp. 1-15

Bagni, G.; Osella, D.; Sturchio, E. \& Mascini, M. (2006). Deoxyribonucleic acid (DNA) biosensors for environmental risk assessment and drug studies. Analytica Chimica Acta, Vol. 573-574, (2006), pp. 81-89

Bakker, E. (2004). Electrochemical sensors. Analytical Chemistry, Vol. 76, No. 12, (June, 2004), pp. 3285-3298

Banerjee, S.; Chakrabarti, G. \& Bhattacharyya, B. (1997). Colchicine binding to tubulin monomers: A mechanistic study. Biochemistry, Vol. 36, No. 18, (1997), pp. 5600-5606

Bănică, F.; Bodoki, E.; Marian, E.; Vicaş, L. \& Săndulescu, R. (2007). The construction and evaluation of an ion selective diazepam electrode for the potentiometric titration of diazepam. Farmacia, Vol. 55, No. 2, (March-April, 2007), pp. 207-216

Blankert, B.; Hayen, H.; van Leeuwen, S.M.; Karst, U.; Bodoki, E.; Lotrean, S.; Săndulescu, R.; Mora Diez, N.; Dominguez, O.; Arcos, J. \& Kauffmann, J.-M. (2005). Electrochemical, chemical and enzymatic oxidations of phenothiazines. Electroanalysis, Vol. 17, No. 17, (September, 2005), pp. 1501-1510

Bodoki, E.; Laschi, S.; Palchetti, I.; Sandulescu, R. \& Mascini, M. (2009). Electrochemical behavior of conchicine using graphite based screen-printed electrodes. Talanta, Vol. 76, No. 2, (2009), pp. 288-294

Bodoki, E.; Săndulescu, R. \& Roman, L. (2007). Method validation in quantitative electrochemical analysis of colchicine using glassy carbon electrode. Central European Journal of Chemistry, Vol. 5, No. 3, (September, 2007), pp. 766-778

Bonciocat, N.; Marian, I.O.; Săndulescu, R.; Filip, C. \& Lotrean, S. (2003). A new proposal for fast determination of vitamin $B_{2}$ from aqueous pharmaceutical products. Journal of 
Pharmaceutical and Biomedical Analysis, Vol. 32, No. 4-5, (August, 2003), pp. 10931098

Briganti, S.; Camera, E. \& Picardo, M. (2003). Chemical and instrumental approaches to treat hyperpigmentation. Pigment Cell Research, Vol. 16, No. 2, (April 2003), pp. 101-110

Castillo, J.; Gaspar, S.; Leth, S.; Niculescu, M.; Mortari, A.; Bontidean, I. et al. (2004). Biosensors for life quality design, development and applications. Sensors and Actuators B, Vol. 102, No.2, (September 2004), pp. 179-194

Câmpean, A.; Tertiş, M. \& Săndulescu, R. (2011) Electrochemical behavior of some purine derivatives on carbon based electrodes. Central European Journal of Chemistry, (2011), accepted for publication

Chang, G.; Tatsu, Y.; Goto, T.; Imaishi, H. \& Morigaki, K. (2010). Glucose concentration determination based on silica sol-gel encapsulated glucose oxidase optical biosensor arrays. Talanta, Vol. 83, No. 1, (November, 2010), pp. 61-65

Chang, T.S. (2009). An Updated Review of Tyrosinase Inhibitors. International Journal of Molecular Science, Vol. 10, No. 6, (May 2009), pp. 2440-2475

Cosnier, S. \& Innocent, C. (1993). A new strategy for the construction of a tyrosinase-based amperometric phenol and o-diphenol sensor Bioelectrochemistty and Bioenergetics, Vol. 31, No. 2, (July, 1993), pp. 147-160

Cosnier, S. \& Popescu, I.C. (1996). Poly( amphiphilic pyrrole)-tyrosinase-peroxidase electrode for amplified flow injection-amperometric detection of phenol. Analytica Chimica Acta, Vol. 319, No. 1-2, (January, 1996), pp. 145-151

Cosnier, S. (1999). Biomolecule immobilization on electrode surfaces by entrapment or attachment to electrochemically polymerized films. A review. Biosensors and Bioelectronics, Vol. 14, No. 5, (May 1999), pp. 443-456

Cosnier, S.; Mousty, C.; Gondran, G. \& Lepellec, A. (2006). Entrapment of enzyme within organic and inorganic materials for biosensor applications: Comparative study. Materials Science and Engineering C , Vol. 26, No 2-3, ( March 2006), pp. 442-447

Cosnier, S.; Senillou, A.; Grätzel, M.; Comte, P.; Vlachopoulos, N.; Jaffrezic-Renault, N. \& Martelet, C. (1999). A glucose biosensor based on enzyme entrapment within polypyrrole films electrodeposited on mesoporous titanium dioxide. Journal of Electroanalytical Chemistry, Vol. 469, No. 2, (July 1999), pp. 176-181

Cosnier, S.; Szunerits, S.; Marks, R.S.; Lellouche, J.P. \& Perie, K. (2001). Mediated electrochemical detection of catechol by tyrosinase-based poly(dicarbazole) electrodes. Journal of Biochemical and Biophysical Methods, Vol. 50, No. 1, (December, 2001), pp. 65-77

Cristea, C.; Feier, B.; Geneste, F.; Săndulescu, R. \& Moinet, C. (2009). New modified porous electrodes for the removal of heavy metal ions from aqueos solutions. Journal of Environmental Protection and Ecology, No. 3, (2009), pp. 633-640

Cristea, C.; Moinet, C.; Jitaru, M. \& Dărăbanțu, M. (2005). Electroreduction of (1S,2S)-2amino-1-(4-nitrophenyl)-propane-1,3-diol derivatives. Behaviour of electrogenerated species and applications to organic synthesis. Journal of Applied Electrochemistry, Vol. 35, No. 9, (2005), pp. 845-849

Cristea, C.; Moinet, C; Jitaru, M. \& Popescu, I.C. (2005). Electrosynthesis of nitroso compounds from (1S, 2S)-2-amino-1-(4-nitrophenyl)-propane-1,3-diol derivatives. Journal of Applied Electrochemistry, Vol. 35, No.9, (2005), pp. 851-855 
Dominguez Renedo, O.; Alonso-Lomillo, M.A.; \& Arcos Martinez, M.J. (2007). Recent developments in the field of screen-printed electrodes and their related applications. Vol. 73, No. 2, (2007), pp.202-219

Duckworth, H. \& Coleman, J.E. (1970). Determination of metals in $100 \mu \mathrm{l}$ sample volumes by atomic absorption analysis using the "spike-height" method of absorbance measurement. Analytical Biochemistry, Vol. 34, No. 2, (April 1970), pp. 382-386

Geneste, F. \& Moinet, C. (2004). Electrocatalytic activity of a polypyridyl ruthenium-oxo complex covalently attached to a graphite felt electrode. New Journal of Chemistry, Vol. 28, No. 6, (June, 2004), pp. 722-726

Geneste, F. \& Moinet, C. (2005). Electrochemically linking TEMPO to carbon via amine bridges. New Journal of Chemistry, Vol. 29, No. 2, (February, 2005), pp. 269-271

Grieshaber, D.; MacKenzie, R.; Voros, J. \& Reimhult, E. (2008). Electrochemical biosensors sensor principles and architectures. Sensors, Vol. 8, No. 3, (April 2008), pp. 14001458

Hu, Y.J.; Liu, Y.; Zhang, L.X.; Zhao, R.M. \& Qu, S.Sh. (2005). Studies of interaction between colchicine and bovine serum albumin by fluorescence quenching method. Journal of Molecular Structure, Vol. 750, No. 1-3, (2005), pp. 174-178

Jacobs, C.B.; Peairs, M.J. \& Venton, B.J. (2010). Carbon nanotube based electrochemical sensors for biomolecules. Analytica Chimica Acta, Vol. 662, No. 2, (March, 2010), pp. 105-127

Jiang, Y.; Xiao, L.; Zhao, L.; Chen, X.; Wang, X. \& Wong, K. (2006). Optical biosensor for the determination of BOD in seawater, Talanta Vol. 70, No. 1, (August, 2006), pp. 97-103

Kok, F.N.; Bozoglu, F. \& Hasirci, V. (2002). Construction of an acetylcholinesterase-choline oxidase biosensor for aldicarb determination. Biosensors and Bioelectronics, Vol. 17, No. 6-7, (June 2002), pp. 531-539

Kong, T.; Chen, Y.; Ye, Y.; Zhang, K.; Wang, Z. \& Wang, X. (2009). An amperometric glucose biosensor based on the immobilization of glucose oxidase on the $\mathrm{ZnO}$ nanotubes. Sensors and Actuators B, Vol. 138, No. 1, (April, 2009), pp. 344-350

Laschi, S.; Bulukin, E.; Palchetti, I,; Cristea, C. \& Mascini, M. (2008). Disposable electrodes modified with multi-wall carbon nanotubes for biosensor applications. IRBM, Vol. 29, No. 2-3, (April-May 2008), pp. 202-207

Lenigk, R.; Lam, E.; Lai, A.; Wang, H.; Han, Y.; Carlier, P. \& Renneberg, R. (2000). Enzyme biosensor for studying therapeutics of Alzheimer's disease. Biosensors and Bioelectronics, Vol. 15, No. 9-10, (November 2000), pp. 541-547

Liu, X.; Shi, L.; Niu, W.; Li, H. \& Xu, G. (2008). Amperometric glucose biosensor based on single-walled carbon nanohorns. Biosensors and Bioelectronics, Vol. 23, No. 12, (July, 2008), pp. 1887-1890

Loris, J.M.; Martinez-Manez, R.; Padilla-Tosta, M.E.; Pardo, T.; Soto, J.; Beer, P. D.; Cadman, J. \& Smith, D. K. (1999). Cyclic and open-chain aza-oxa ferrocene-functionalized derivatives as receptors for the selective electrochemical sensing of toxic heavy metal ions in aqueous environments, Journal of the Chemical Society, Dalton Transactions, No. 14, (1999), pp. 2359-2370

Marian, I.O.; Bonciocat, N.; Săndulescu, R. \& Filip, C. (2001). Direct voltammetry for vitamin $\mathrm{B}_{2}$ determination in aqueous solutions by using a glassy carbon electrode. Journal of Pharmaceutical and Biomedical Analysis, Vol. 24, No. 5-6, (March, 2001), pp. 1175-1179 
Marian, I.O.; Săndulescu, R. \& Bonciocat, N. (2000). Diffusion coefficient and concentration determination of ascorbic acid in the Fredholm alternative using a carbon paste, Journal of Pharmaceutical and Biomedical Analysis, Vol. 23, No. 1, (August, 2000), pp. 227-230

Menon, S.; Fleck, R.W.; Yong, G. \& Strothkamp, K.G. (1990). Benzoic acid inhibition of the alpha, beta and gama isozymes of Agaricus bisporus tyrosinase. Archives of Biochemistry and Biophysics, Vol. 280, No. 1, (July 1990), pp. 27-32

Mousty, C.; Lepellec, A.; Cosnier, S.; Novoa, A. \& Marks, R. (2991). Fabrication of organic phase biosensors based on multilayered polyphenol oxidase protected by an alginate coating. Electrochemistry Communication, Vol. 3, No.12, (December 2001), pp. 727-732

Nasraoui, R.; Floner, D. \& Geneste, F. (2009). Analytical performances of a flow electrochemical sensor for preconcentration and stripping voltammetry of metal ions. Journal of Electroanalytical Chemistry, Vol. 629, No. 1-2, (April, 2009), pp. 30-34

Nasraoui, R.; Floner, D. \& Geneste, F. (2010). Improvement in performance of a flow electrochemical sensor by using carbamoyl-arms polyazamacrocycle for the preconcentration of lead ions onto the electrode. Electrochemistry Communications, Vol. 12, No. 1, (January, 2010), pp. 98-100

Nasraoui, R.; Floner, D.; Paul-Roth, C. \& Geneste, F. (2010). Flow electroanalytical system based on cyclam-modified graphite felt electrodes for lead detection. Journal of Electroanalytical Chemistry, Vol. 638, No. 1, (January, 2010), pp. 9-14

Nenkova, R.; Ivanova, D.; Vladimirova, J. \& Godjevargova, T. (2010). New amperometric glucose biosensor based on cross-linking of glucose oxidase on silica gel/multiwalled carbon nanotubes/polyacrylonitrile nanocomposite film. Sensors and Actuators B, Vol. 148, No. 1, (June, 2010), pp. 59-65

Olea, D.; Viratelle, O. \& Faure, C. (2008). Polypyrrole-glucose oxidase biosensor: Effect of enzyme encapsulation in multilamellar vesicles on analytical properties. Biosensors and Bioelectronics, Vol. 23, No. 6, (January, 2008), pp. 788-794

Paleček, E.; Fojta, M.; Tomschik, M. \& Wang, J. (1998). Electrochemical biosensors for DNA hybridization and DNA damage. Biosensors and Bioelectronics, Vol. 13, No. 6, (1998), pp. 621-628

Pan, D.; Chen, J.; Yao, Sh.; Nie, L.; Xia, J. \& Tao, W. (2005). Amperometric glucose biosensor based on immobilization of glucose oxidase in electropolymerized o-aminophenol film at copper-modified gold electrode. Sensors and Actuators B, Vol. 104, No. 1, (January, 2005), pp. 68-74

Prodromidis, M.I. \& Karayannis, M.I. (2002). Enzyme based amperometric biosensors for food analysis, Electroanalysis Vol. 14, No. 2 (2002) pp. 241-261

Ramanavicius, A.; Kausaite, A. \& Ramanaviciene, A. (2005). Polypyrrole-coated glucose oxidase nanoparticles for biosensor design. Sensors and Actuators B, Vol. 111-112, (November, 2005), pp. 532-539

Reviejo, A.J.; Liu, F. \& Pingarron, J.M. (1994). Amperometric biosensors in reversed micelles. Journal of Electroanalytical Chemistry, Vol. 374, No. 1-2, (August 1994), pp.133-139

Rogers, K.R. (2006). Recent advances in biosensor techniques for environmental monitoring. Analytica Chimica Acta, Vol. 568, No. 1-2, (May 2006), pp. 222-231

Rubianes, M.D. \& Rivas, G.A. (2007). Dispersion of multi-wall carbon nanotubes in polyethylenimine: A new alternative for preparing electrochemical sensors. Electrochemistry Communications, Vol. 9, No. 3, (March, 2007), pp. 480-484 
Rubio Retama, J.; Lopez Cabarcos, E.; Mecerreyesc, D. \& Lopez-Ruiz, B. (2004). Design of an amperometric biosensor using polypyrrole-microgel composites containing glucose oxidase. Biosensors and Bioelectronics, Vol. 20, No. 6, (December, 2004), pp. 1111-1117

Rusling, J.F. (2010). Biomolecular Films. Design, Function, and Applications, Surfactant Science Series, Vol.111, Marcel Decker, Inc., 2003, New York; Pier Andrea Serra, Biosensors, InTech, 2010

Sanchez-Paniagua Lopez, M.; Lopez-Cabarcos, E. \& Lopez-Ruiz, B. (2006). Organic phase enzyme electrodes. Biomolecular Engineering, Vol. 23, No. 4, (September 2006), pp. 135-147

Săndulescu, R.; Mirel, S. \& Oprean, R. (2000). The development of spectrophotometric and electrochemical methods for ascorbic acid and acetaminophen determination and their applications in the analysis of effervescent dosage forms. Journal of Pharmaceutical and Biomedical Analysis, Vol. 23, No. 1, (August, 2000), pp. 77-87

Săndulescu, R.; Mirel, S.; Oprean, R. \& Lotrean, S. (2000). Comparative electrochemical study of some phenothiazines with carbon paste, solid carbon paste and glassy carbon electrodes. Collection of Czechoslovak Chemical Communications, Vol. 65, No. 6, (June, 2000), pp. 1014-1028

Shan, D.; Li, Q.; Xue, H. \& Cosnier, S. (2008). A highly reversible and sensitive tyrosinase inhibition-based amperometric biosensor for benzoic acid monitoring. Sensors and Actuators B, Vol. 134, No. 2, (September 2008), pp. 1016-1021

Shan, D.; Zhang, J.; Xue, H.; Zhang, Y.; Cosnier, S. \& Ding, Sh. (2009). Polycrystalline bismuth oxide films for development of amperometric biosensor for phenolic compounds. Biosensors and Bioelectronics, Vol. 24, No. 12, (August, 2009), pp. 36713676

Shan, D.; Zhu, M.; Han, E., Xue, H. \& Cosnier. (2007). Calcium carbonate nanoparticles: A host matrix for the construction of highly sensitive amperometric phenol biosensor. Biosensors and Bioelectronics, Vol. 23, No. 5, (December, 2007), pp. 648-654

Sima, V.; Cristea, C.; Bodoki, E.; Duțu, G. \& Săndulescu, R. (2010). Screen-printed electrodes modified with HRP- zirconium alcoxide film for the development of a biosensor for acetaminophen detection. Central European Journal of Chemistry, Vol. 8, No. 5, (October 2010), pp. 1034-1040

Sima, V.; Cristea, C.; Lapadus, F.; Marian, I.O.; Marian, A. \& Sandulescu, R. (2010). Electroanalytical properties of a novel biosensor modified with zirconium alcoxide porous gels for the detection of acetaminophen. Journal of Pharmaceutical and Biomedical Analysis, Vol. 48, No. 4, (December 2008), pp. 1195-1200

Sima, V.H.; Patris, S.; Aydogmus, Z.; Sarakbi, A.; Sandulescu, R. \& Kauffmann, J.M. (2011). Tyrosinase immobilized magnetic nanobeads for the amperometric assay of enzyme inhibitors: Application to the skin whitening agents. Talanta, Vol. 83, No. 3, (January 2011), pp. 980-987

Teles, F.R.R. \& Fonseca, L.P. Trends in DNA biosensors. Talanta, Vol.77, No. 2, (2008), pp. 606-623

Thevenot, D.R.; Toth, K.; Durst, R.A. \& Wilson, G.S. (2001). Electrochemical biosensors: recommended definitions and classification. Biosensors and Bioelectronics, Vol. 16, No. 1-2, (January 2001), pp. 121-131

Wang, J. (1999). Amperometric biosensors for clinical and therapeutic drug monitoring: a review. Journal of Pharmaceutical and Biomedical Analysis, Vol. 19, No. 1-2, (February 1999), pp. 47-53 
Wu, B.; Zhang, G.; Shuang, Sh \& Choi, M.M.F. (2004). Biosensors for determination of glucose with glucose oxidase immobilized on an eggshell membrane. Talanta, Vol. 64, No. 2, (Octomber, 2004), pp. 546-553

Xu, H.; Hou F. \& Zhang, X. (2011). Electrochemical investigation on the interaction between colchicine and DNA. Current Physical Chemistry, Vol.1, No. 1, (2011), pp.11-15

$\mathrm{Xu}$, Z.; Chen, X. \& Dong, S. (2006). Electrochemical biosensors based on advanced bioimmobilization matrices. Trends in Analytical Chemistry, Vol. 25, No. 9, (October 2006), pp. 899-908

Yang, X.; Zhou, Z.; Xiao, D. \& Choi, M.M.F. (2006). A fluorescent glucose biosensor based on immobilized glucose oxidase on bamboo inner shell membrane. Biosenosors and Bioelectronics, Vol. 21, No. 8, (February, 2006), pp. 1613-1620

Yang, Y.; Yang, H.; Yang, M; Liu, Y.; Shen, G. \& Yu. R. (2004). Amperometric glucose biosensor based on a surface treated nanoporous $\mathrm{ZrO}_{2} /$ Chitosan composite film as immobilization matrix, Analitica Chimica Acta, Vol. 525, No. 2, (November, 2004), pp. 213-220

Yu, D.; Blankert, B.; Bodoki, E.; Bollo, S.; Vire, J.C.; Sandulescu, R.; Nomura, A. \& Kauffmann, J.M. (2006). Amperometric biosensor based on horseradish peroxidaseimmobilised magnetic microparticles. Sensors and Actuators B, Vol. 113, No. 2, (February 2006), pp. 749-754

Yu, D.; Dominguez, R.O.; Blankert, B.; Sima, V.; Sandulescu, R.; Arcos, J. \& Kauffmman, J.M. (2006). A peroxidase-based biosensor supported by nanoporous magnetic silica microparticles for acetaminophen biotransformation and inhibition studies. Electroanalysis, Vol. 18, No. 17, (September 2006), pp. 1637-1642 


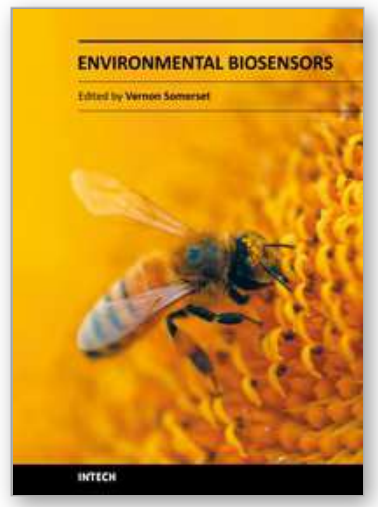

\author{
Environmental Biosensors \\ Edited by Prof. Vernon Somerset
}

ISBN 978-953-307-486-3

Hard cover, 356 pages

Publisher InTech

Published online 18, July, 2011

Published in print edition July, 2011

This book is a collection of contributions from leading specialists on the topic of biosensors for health, environment and biosecurity. It is divided into three sections with headings of current trends and developments; materials design and developments; and detection and monitoring. In the section on current trends and developments, topics such as biosensor applications for environmental and water monitoring, agroindustry applications, and trends in the detection of nerve agents and pesticides are discussed. The section on materials design and developments deals with topics on new materials for biosensor construction, polymerbased microsystems, silicon and silicon-related surfaces for biosensor applications, including hybrid film biosensor systems. Finally, in the detection and monitoring section, the specific topics covered deal with enzyme-based biosensors for phenol detection, ultra-sensitive fluorescence sensors, the determination of biochemical oxygen demand, and sensors for pharmaceutical and environmental analysis.

\title{
How to reference
}

In order to correctly reference this scholarly work, feel free to copy and paste the following:

Robert Sandulescu, Cecilia Cristea, Veronica Harceaga and Ede Bodoki (2011). Electrochemical sensors and biosensors for the pharmaceutical and environmental analysis, Environmental Biosensors, Prof. Vernon Somerset (Ed.), ISBN: 978-953-307-486-3, InTech, Available from:

http://www.intechopen.com/books/environmental-biosensors/electrochemical-sensors-and-biosensors-for-thepharmaceutical-and-environmental-analysis

\section{INTECH}

open science | open minds

\section{InTech Europe}

University Campus STeP Ri

Slavka Krautzeka 83/A

51000 Rijeka, Croatia

Phone: +385 (51) 770447

Fax: +385 (51) 686166

www.intechopen.com

\section{InTech China}

Unit 405, Office Block, Hotel Equatorial Shanghai

No.65, Yan An Road (West), Shanghai, 200040, China

中国上海市延安西路65号上海国际贵都大饭店办公楼405单元

Phone: +86-21-62489820

Fax: $+86-21-62489821$ 
(C) 2011 The Author(s). Licensee IntechOpen. This chapter is distributed under the terms of the Creative Commons Attribution-NonCommercialShareAlike-3.0 License, which permits use, distribution and reproduction for non-commercial purposes, provided the original is properly cited and derivative works building on this content are distributed under the same license. 